\title{
Controlling the Biological Fate of Micellar Nanoparticles: Balancing Stealth and Targeting
}

\begin{tabular}{|c|c|}
\hline Journal: & ACS Nano \\
\hline Manuscript ID & $\mathrm{nn}-2020-06033 \mathrm{~s} . \mathrm{R} 3$ \\
\hline Manuscript Type: & Article \\
\hline $\begin{array}{r}\text { Date Submitted by the } \\
\text { Author: }\end{array}$ & 09-Sep-2020 \\
\hline Complete List of Authors: & $\begin{array}{l}\text { Sivaram, Amal; University of Queensland Australian Institute for } \\
\text { Bioengineering and Nanotechnology; The Centre for Advanced Imaging; } \\
\text { The University of Queensland } \\
\text { Wardiana, Andri; University of Queensland Australian Institute for } \\
\text { Bioengineering and Nanotechnology } \\
\text { Alcantara, Sheilajen ; University of Melbourne, Microbiology and } \\
\text { Immunology; University of Melbourne, Microbiology and Immunology } \\
\text { Sonderegger, Stefan; University of Queensland Australian Institute for } \\
\text { Bioengineering and Nanotechnology } \\
\text { Fletcher, Nicholas; University of Queensland, Centre for Advanced } \\
\text { Imaging; The Centre for Advanced Imaging; The University of } \\
\text { Queensland } \\
\text { Houston, Zachary; University of Queensland Australian Institute for } \\
\text { Bioengineering and Nanotechnology; The Centre for Advanced Imaging; } \\
\text { The University of Queensland } \\
\text { Howard, Christopher; University of Queensland Australian Institute for } \\
\text { Bioengineering and Nanotechnology; The University of Queensland } \\
\text { Mahler, Stephen; University of Queensland, Australian Institue of } \\
\text { Bioengineering \& Nanaotechnology; The University of Queensland } \\
\text { Alexander, Cameron; University of Nottingham, School of Pharmacy } \\
\text { Kent, Stephen; University of Melbourne; University of Melbourne, } \\
\text { Microbiology and Immunology } \\
\text { Bell, Craig; University of Queensland, Australian Institute for } \\
\text { Bioengineering and Nanotechnology; The Centre for Advanced Imaging; } \\
\text { The University of Queensland } \\
\text { Thurecht, Kristofer; The University of Queensland, Australian Institute } \\
\text { for Bioengineering and Nanotechnology; The University of Queensland, } \\
\text { Centre for Advanced Imaging; The University of Queensland; The } \\
\text { University of Queensland }\end{array}$ \\
\hline
\end{tabular}




\section{Controlling the Biological Fate of Micellar}

\section{Nanoparticles: Balancing Stealth and Targeting}

Amal J. Sivaram ${ }^{1,2,3}$, Andri Wardiana ${ }^{1}$, Sheilajen Alcantara ${ }^{5}$, Stefan E. Sonderegger ${ }^{1}$, Nicholas

L. Fletcher ${ }^{1,2,3}$, Zachary H. Houston ${ }^{1,2,3}$, Christopher B. Howard ${ }^{1,6}$, Stephen M. Mahler ${ }^{1,6}$, Cameron Alexander ${ }^{4}$, Stephen J. Kent ${ }^{5}$, Craig A. Bell ${ }^{1,2,3}$, Kristofer J. Thurecht ${ }^{1,2,3 *}$

${ }^{1}$ Australian Institute for Bioengineering and Nanotechnology, The University of Queensland, St Lucia, QLD 4072, Australia

${ }^{2}$ Centre for Advanced Imaging, The University of Queensland, St Lucia, QLD 4072, Australia

${ }^{3}$ ARC Centre of Excellence in Convergent Bio-Nano Science and Technology, and ARC Training Centre for Innovation in Biomedical Imaging Technology, The University of Queensland, St Lucia, QLD 4072, Australia

${ }^{4}$ School of Pharmacy, The University of Nottingham, Nottingham NG7 2RD, United Kingdom

${ }^{5} \mathrm{ARC}$ Centre of Excellence in Convergent Bio-Nano Science and Technology, and the Department of Microbiology and Immunology, The University of Melbourne, at the Peter Doherty Institute for Infection and Immunity, Parkville, Victoria 3010, Australia ${ }^{6}$ ARC Training Centre for Biopharmaceutical Innovation, The University of Queensland, St Lucia, QLD 4072, Australia

*Corresponding author, E-mail: k.thurecht@uq.edu.au (Kristofer J. Thurecht) 


\begin{abstract}
Integrating nanomaterials with biological entities has led to the development of diagnostic tools and biotechnology-derived therapeutic products. However, to optimise the design of these hybrid bionanomaterials, it is essential to understand how controlling the biological interactions will influence desired outcomes. Ultimately, this knowledge will allow more rapid translation from the bench to the clinic. In this paper, we developed a micellar system that was assembled using modular antibody-polymer amphiphilic materials. The amphiphilic nature was established using either polyethylene glycol (PEG) or a single-chain variable fragment (scFv) from an antibody as the hydrophile, and a thermoresponsive polymer (poly(oligoethylene glycol) methyl ether methacrylate) as the hydrophobe. By varying the ratios of these components, a series of nanoparticles with different antibody content was self-assembled, where the surface presentation of targeting ligand was carefully controlled. In vitro and in vivo analysis of these systems identified a mismatch between the optimal targeting ligand density to achieve maximum cell association in vitro compared to tumour accumulation in vivo. For this system, we determined an optimum antibody density for both longer circulation and enhanced targeting to tumours that balanced stealthiness of the particle (to evade immune recognition as determined in both mouse models and in whole human blood) with enhanced accumulation achieved through receptor binding on tumour cells in solid tumours. This approach provides fundamental insights into how different antibody densities affect the interaction of designed nanoparticles with both target cells and immune cells, thereby offering a method to probe the intricate interplay between increased targeting efficiency versus the subsequent immune response to nanoparticles.
\end{abstract}


KEYWORDS: single-chain variable fragment, polyethylene glycol, antibody density, micellar nanoparticles, tumour targeting,

Nanomedicines are now evolving as precisely engineered nanomaterials that offer significant potential to overcome many limitations of conventional anti-cancer drugs. ${ }^{1}$ The therapeutic efficacies of current drugs are limited due to unfavourable physicochemical properties such as low solubility, instability, toxicity issues due to lack of selectivity, and poor pharmacokinetics. In contrast, the properties of new nanomaterials can be designed to enhance biocompatibility, reduce toxicity, control drug release, and increase circulation time in the body, enabled much improved therapeutic delivery. ${ }^{2}$ Furthermore, nanomaterials offering theranostic features can enable real-time monitoring of site-specific drug delivery to the cancer target. ${ }^{3}$ Although nanomaterials have been intensively investigated for delivering drugs to the solid tumours, there are studies showing discrepancies with the number of nanoparticles reaching tumour sites versus the administered nanoparticle dose. In a meta-analysis of a wide range of nanomedicines administered to mice, it was suggested that on average only $0.7 \%$ of the injected dose is retained in the solid tumours, indicating the exceptional challenge for translation of nanomedicines. ${ }^{4}$ In order to enhance delivery efficiency, it is vital to understand the factors that influence the pharmacokinetic profile and behaviour of nanomaterials. Upon intravenous administration, nanoparticles initially interact with blood components before distributing throughout the various tissues, including the target tumour site. Longer blood circulation times are a critical factor in achieving successful tumour accumulation, which ultimately depends on how well nanoparticles overcome the biological barriers and clearance systems designed to exclude and remove exogenous materials. For nanomaterials, a major problem is rapid coating by opsonin proteins and subsequent clearance by the mononuclear phagocytic system (MPS). ${ }^{5,6}$ The blood 
residence times of nanoparticles can be influenced by their physicochemical properties such as shape, surface charge, size, and ligand densities. ${ }^{7}$ Nonetheless, an in-depth analysis of the relationships between physicochemical properties, body clearance and the overall targeting efficacies of nanoparticles has yet to be conducted and correlated fully across a coherent set of particles.

Research to date has established some rules for consideration when designing nanomaterials for drug delivery. For example, it is well reported that nanoparticle sizes in the range of $20-$ $30 \mathrm{~nm}$ results in higher receptor-mediated uptake, while nanoparticles in the $20-100 \mathrm{~nm}$ range can be used for enhanced liver accumulation. ${ }^{8}$ However, there is by no means a consensus in the literature as to what is the most ideal size of particle for optimal therapeutic efficiency and most nanoparticle strategies develop materials that span particle sizes between 20-200 nm. It is also well established (but not precisely quantified) that "targeted" nanomaterials show greater uptake and accumulation in cells, mostly under in vitro conditions. Often when these studies are translated to animals, however, incorporating a higher density of targeting protein functionality to enhance recognition at an intended disease site increases immune recognition and expedites clearance of nanomaterials; in some cases, such modulation with targeting ligands can actually decrease the tumour accumulation compared to the untargeted nanomedicine. ${ }^{9}$ Despite the wealth of data on new and sophisticated drug delivery vehicles, there are significant exceptions to these generalised rules, and there is no clear methodology for optimising targeting approaches for these materials. ${ }^{10}$ Furthermore, these generalised rules that often are used to design new materials seldom transfer between the bench, the cell in a dish, and the body, leading to a disconnect between materials design and observed properties. ${ }^{9}$ One point of significant interest is the influence of targeting ligand density on nanomaterial interactions with cell surface receptors. ${ }^{11}$ A few studies have investigated how the number and 
density of ligands influence the internalisation and subsequent cellular processing of bionanomaterials, but there is limited information on how the surface density of ligands affects the physiological behaviour of nanomaterials in circulation, and how this ultimately translates to tumour accumulation. ${ }^{12,13}$ Nonetheless, the limited data available suggests that there is a threshold at which clustering of ligands saturates surface receptors, often leading to modified internalisation pathways and variable efficacy of delivered therapeutics. ${ }^{14,15}$ The challenge is to develop strategies to design next-generation nanomaterials, accounting for the competing requirements of enhanced cellular uptake through higher ligand density, with embedded "stealthiness" to avoid rapid immune recognition and clearance. This epitomises the general observation that what is evidenced in vitro, is difficult to transition to in vivo, due to the absence of the competing requirement for stealthiness in the majority of in vitro assays.

To date, the majority of studies looking at receptor clustering effects have focused on the effect of small molecule ligands, such as the folate receptor. ${ }^{16}$ One reason for this is the intrinsic complexity associated with biomolecule assemblies, complicating the development of welldefined systems where this effect can be monitored universally. This project progresses our understanding of targeting in a complex biological environment, through the development of micellar systems specifically designed to control the targeting ligand density of more biologically relevant protein-based ligands through the self-assembly process. This is achieved using thermoresponsive polymers, which can interact with the proteins in aqueous conditions without denaturing them.

In this study, we synthesised an amphiphilic antibody-polymer conjugate that was selfassembled to form micelles in which the surface constitutes a defined mixture of stealthy polymers and an antibody fragment (single-chain variable fragment $-\mathrm{scFv}$ ) that shows high affinity for receptors upregulated on cancer cells. The advantage of this approach is that the 
relatively small size of scFvs avoids steric effects associated with whole monoclonal antibodies, affording greater control over packing density, while the polymeric materials offer well-understood physicochemical tuneability that is required to develop such complex, yet ordered systems. By modulating the incorporation of antibody-polymer hybrid amphiphiles through co-assembly with purely synthetic polymer amphiphiles, the density of antibody fragments on the micelle can be manipulated across a significant range. Hence, the effect of ligand density on how the micelles bind to cell surface receptors and how it dictates the cellular uptake pathways of particular nanomaterials can be investigated. This can then be compared to the ultimate biological fate of the micelles upon injection into tumour-bearing mice, where the nanoparticles are exposed to a greater complement of biological barriers that limit tumour accumulation. This offers a robust approach to develop an in-depth understanding of how these fundamental properties can be utilised to enhance cellular uptake and influence biodistribution. Figure 1 schematically represents the hypothesis of this study, that increased antibody will lead to maximum binding efficiency in vitro, but also leads to greater immune recognition that often manifests in reduced tumour accumulation. 

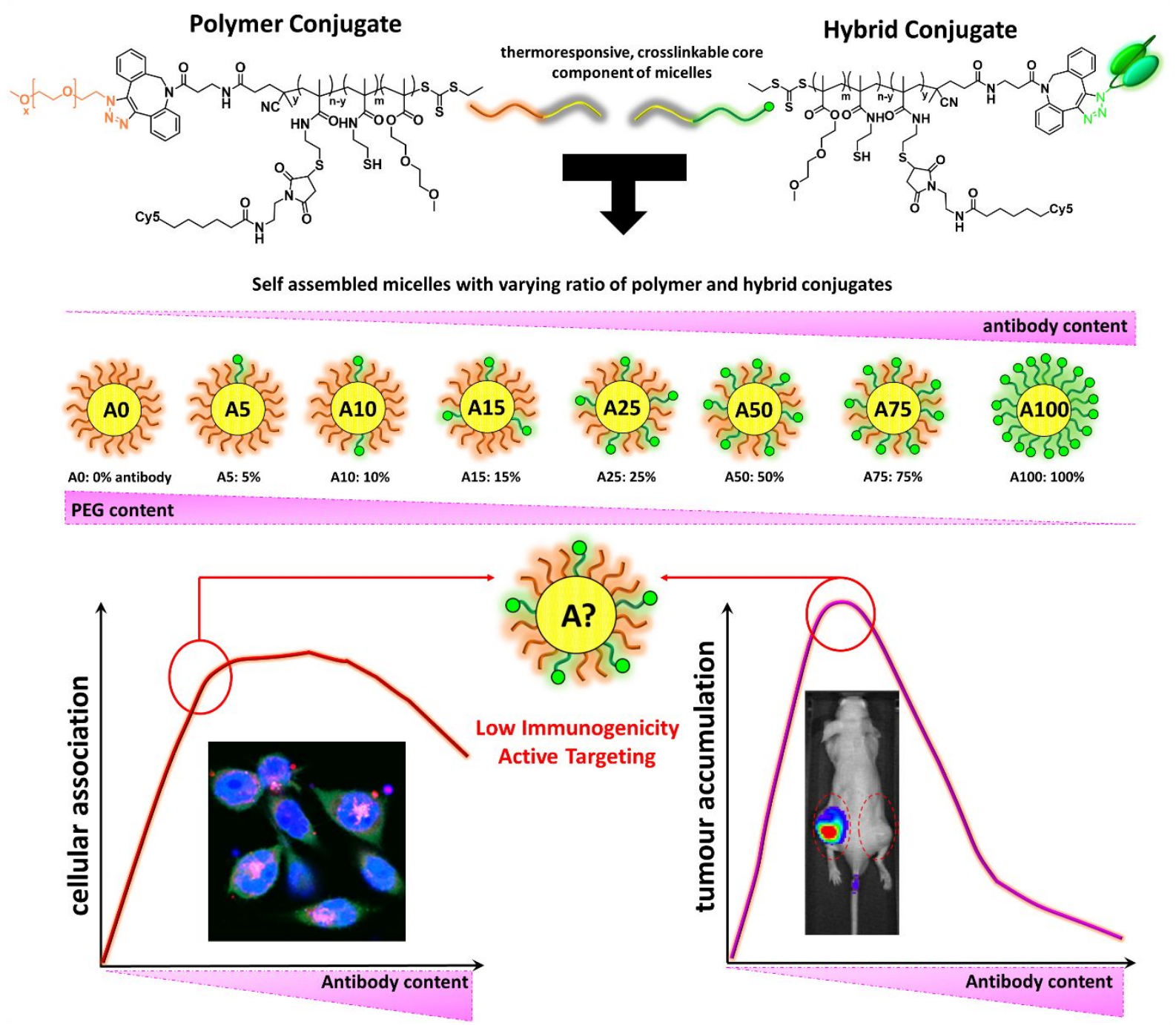

Figure 1. Schematic diagram postulating the influence of ligand density on nanoparticle uptake in vitro and in vivo. An optimum ratio of antibody to PEG components on micelles may lead to an improvement in the therapeutic efficacy due to enhanced targeting and lower immune response.

\section{RESULTS AND DISCUSSION}

We set out to design a nanomaterial system where precise control over the ratio of antibody and PEG components could be achieved, allowing us to synthesise a range of micelles incorporating various antibody densities so we could understand their biological fate. The design elements of this study required a number of important conceptual and materials 
advances. First, a synthetic component was required that could be coupled with proteins under aqueous conditions (i.e. water-soluble), but which would also act as the hydrophobe for assembly into micelles. It was also necessary to have a mechanism to crosslink the hydrophobic core for enhanced stability of the assemblies. Second, a suitable mechanism for coupling the antibody fragment to the hydrophobe was needed, as well as a defined way of tracking successful incorporation of the different components into the assemblies.

Thermoresponsive, crosslinkable polymer chain as the hydrophobic component. A key challenge in the development of amphiphilic polymer-protein conjugates is the stringent reaction conditions required for antibody modifications. For example, such reactions cannot be undertaken in organic solvents (as this leads to loss of tertiary structure); however in water hydrophobic polymers are not soluble, and heterogeneous conjugation is poor yielding and uncontrolled. ${ }^{17}$ Thus, we sought to develop a thermoresponsive "hydrophobic" component for the amphiphilic system using di(ethylene glycol) methyl ether methacrylate (DEGMA) and pentafluorophenyl methacrylate (MAPFP) in which coupling to the antibody can be undertaken in water at low temperature, but upon an increase in temperature above the lower critical solution temperature (LCST) the polymer becomes insoluble. To this end, we sought to develop end-functional responsive polymers that also contained a mid-chain reactive group for crosslinking the final micellar assemblies. 4-cyano-4(ethylsulfanylthiocarbonylsulfanyl)pentanoic acid (CEPA) was employed as the reversible addition-fragmentation chain transfer (RAFT) agent to provide control over the radical copolymerisation of these two monomers as well as impart acid chain-end functionality that could then be modified with a dibenzocyclooctyne (DBCO) amine linker for downstream coupling of the solvent-sensitive antibody fragments through strain promoted alkyne azide cycloaddition (SPAAC). ${ }^{18}$ The generalised scheme and selective characterisation of each 
component is presented in Figure 2A. Using CEPA, statistical copolymers of p(DEGMA-coMAPFP) were synthesised with defined molecular weights and dispersities (Table 1). The molecular weights of $\mathrm{p}(\mathrm{DEGMA}-\mathrm{co}-\mathrm{MAPFP})$ were calculated using ${ }^{1} \mathrm{H}$ NMR by integrating the DEGMA side-chain protons at $4.01-4.24 \mathrm{ppm}$ (for DEGMA contribution), the $\mathrm{p}$ (MAPFP) and $\mathrm{p}$ (DEGMA) methyl protons at $0.8-1.28 \mathrm{ppm}$ and subtracting the contribution from DEGMA (to calculate the MAPFP contribution), and calibrating to the methylene protons adjacent to the terminal trithiocarbonate $(3.22 \mathrm{ppm}) .{ }^{1} \mathrm{H}$ and ${ }^{19} \mathrm{~F}$ NMR spectra of the $\mathrm{p}$ (DEGMA-co-MAPFP) copolymer can be seen in Figure 2B and 2C, respectively, and SEC results are shown in Table 1.

Table 1. Summary of physicochemical characteristics of the hydrophobic component after each modification.

\begin{tabular}{|c|l|c|c|c|c|}
\hline Si No. & Sample & $\begin{array}{c}\mathbf{M}_{\mathbf{n}}{ }^{\mathbf{a}} \\
\mathbf{( k D a )}\end{array}$ & $\boldsymbol{\#}_{\mathbf{M}}{ }^{\mathbf{b}}$ & $\begin{array}{c}\text { Yield } \\
\mathbf{( \% )}\end{array}$ & $\begin{array}{c}\mathbf{L C S T}^{\mathbf{c}} \\
\left.\mathbf{(}^{\circ} \mathbf{C}\right)\end{array}$ \\
\hline $\mathbf{1}$ & p(DEGMA-co-MAPFP) & 6.0 & 1.30 & 92 & 10 \\
\hline $\mathbf{2}$ & p(DEGMA-co-MACYS) & 5.5 & 1.50 & 85 & 16 \\
\hline $\mathbf{3}$ & DBCO-p(DEGMA-co-MACYS) & 6.5 & 1.60 & 82 & 16 \\
\hline
\end{tabular}

a Molecular weight obtained by SEC analysis in THF using PS standards. ${ }^{b}$ Dispersity $\left(\bigoplus_{\mathrm{M}}\right)$ obtained by SEC analysis in THF using PS standards. ${ }^{c}$ Onset temperature of the thermoresponsive transition.

A key element of our design was to ensure the stability of these micelles, both during in vitro and in vivo evaluation. To this end, we incorporated sulfhydryl units within the polymer chains to allow for disulfide-mediated crosslinking between polymer chains within the final micellar assemblies. The pentafluorophenyl (PFP) group within the copolymer was subsequently modified to present thiol groups through post-polymerisation modification with cysteamine (CYS). ${ }^{19}$ Near quantitative substitution of the pentafluorophenyl groups with CYS to form $\mathrm{p}$ (DEGMA-co-MACYS) was achieved using the polar aprotic solvent $N, N$-dimethylformamide 
(DMF), which is well-known to promote $\mathrm{S}_{\mathrm{N}} 2$ substitution reactions. ${ }^{20}$ This process was monitored through the disappearance of the fluorine peaks $(-151.7,-152.7$ (ortho), -158.2 (para), and -163.3 (meta) ppm) in the ${ }^{19} \mathrm{~F}$ NMR spectrum of the polymer (Figure 2C) following amidation. Successful coupling of CYS to the polymer was also observed indirectly, with a significant change in the polymer LCST following modification (Table 1). The LCST onset temperature shifted from $10{ }^{\circ} \mathrm{C}$ to $16{ }^{\circ} \mathrm{C}$ upon CYS modification (Figure S2), presumably due to modulation of the overall copolymer hydrophobicity through replacement of the PFP group with the more hydrophilic thiol. Moreover, these thiol groups present potential crosslinking sites initiated through disulfide formation that would exhibit redox responsiveness for downstream application of these nanomaterials in drug delivery. ${ }^{21}$

The final step in the preparation of the responsive hydrophobic component of the amphiphile was chain-end modification to facilitate rapid conjugation of either the biological entity or PEG hydrophile, followed by incorporation of a fluorescent dye (Cy5 maleimide) for tracking purposes. The DBCO-p(DEGMA-co-MACYS) copolymer were conveniently prepared through amidation with a heterobifunctional linker (Figure 2). ${ }^{22}$ Successful modification was monitored by UV-Vis spectroscopy with the appearance of the characteristic absorbance peak of $\mathrm{DBCO}$ at $309 \mathrm{~nm}$ (Figure 2D) and ${ }^{1} \mathrm{H}$ NMR which showed the presence of aromatic peaks between 7.3 - $7.65 \mathrm{ppm}$ assigned to DBCO (Figure S1). 

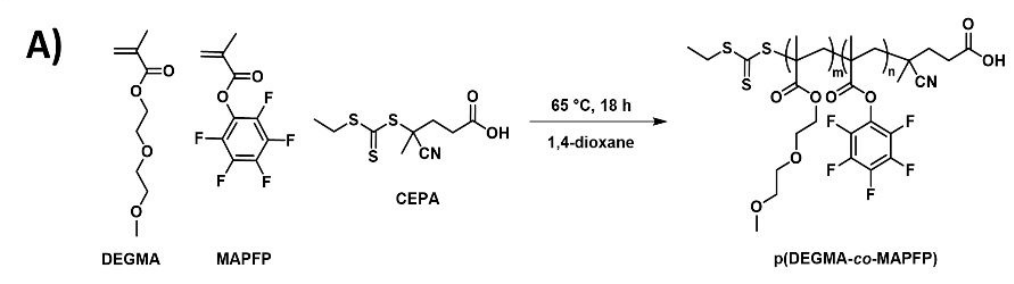
respectively.

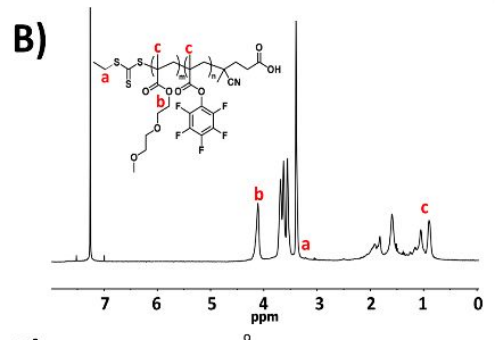

C)

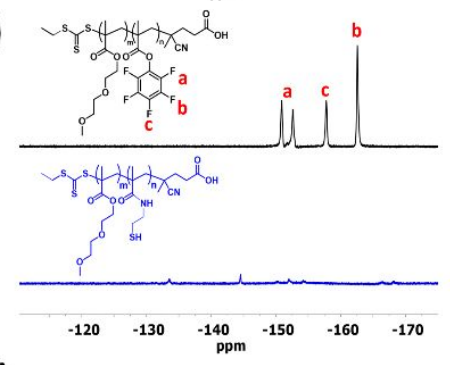

D)

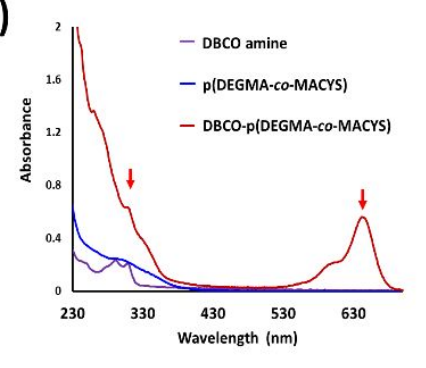

Figure 2. (A) Reaction scheme showing the synthesis of the thermoresponsive, crosslinkable polymer chain for the hydrophobic component of the amphiphiles (B) ${ }^{1} \mathrm{H}$ NMR $(500 \mathrm{MHz}$, $\left.\mathrm{CDCl}_{3}\right)$ spectrum of $\mathrm{p}(\mathrm{DEGMA}-\mathrm{co}$-MAPFP) with (a) methylene protons adjacent to the trithiocarbonate, (b) (DEGMA) side-chain protons, and (c) p(MAPFP) and p(DEGMA) methyl protons. (C) $\left.{ }^{19} \mathrm{~F} \mathrm{NMR} \mathrm{(470} \mathrm{MHz}, \mathrm{CDCl}_{3}\right)$ spectra of $\mathrm{p}$ (DEGMA-co-MAPFP) copolymer exhibiting the ortho-, meta-, and para- signals associated with the PFP repeat units (black), and after reaction of the polymer with CYS resulting in $\mathrm{p}$ (DEGMA-co-MACYS) copolymer (blue) indicating almost complete success of the amidation reaction. (D) UV-Vis spectra in methanol of DBCO amine (purple), p(DEGMA-co-MACYS) (blue) and DBCO-p(DEGMA-coMACYS) (red) showing the incorporation of DBCO and Cy5 peaks at 309 and $647 \mathrm{~nm}$ 
This was followed by conjugation of Cy5 maleimide dye onto a small portion of the thiol groups in the polymer to provide a diagnostic handle for the hydrophobic block, and the subsequent product was characterised using UV-Vis spectroscopy, which showed the characteristic absorbance peak of Cy5 at $647 \mathrm{~nm}$. The LCST of the resulting polymer system was evaluated and shown to be $16{ }^{\circ} \mathrm{C}$, suggesting that successful protein conjugation could occur at temperatures below this point when the polymer was soluble in water, but subsequent heating above this point would lead to self-assembly of the polymer chains (Figure S2). Table 1 summarises the physicochemical properties of the hydrophobic component after subsequent modifications.

Development of amphiphilic conjugates. The thermoresponsive "hydrophobic" polymer described above was then coupled with either $\mathrm{scFv}-\mathrm{N}_{3}$ or PEG-N $\mathrm{N}_{3}$ hydrophiles through SPAAC reaction, a fast catalyst-free click chemistry method, as a convenient route to creating amphiphilic block copolymers. ${ }^{18}$ As a model antibody system, an scFv $(25 \mathrm{kDa})$ of the established Prostate-Specific Membrane Antigen (PSMA) targeting antibody, J591, was engineered and produced in bacteria. ${ }^{23}$ Moreover, an unnatural amino acid containing azide functionality was engineered into the $\mathrm{N}$-terminus of the $\mathrm{scFv}$ to allow convenient azide-alkyne click reactions to occur. ${ }^{24}$ The $\mathrm{scFv}$ was subsequently conjugated to DBCO-p(DEGMA-coMACYS) by incubation in PBS at $4{ }^{\circ} \mathrm{C}$ for $24 \mathrm{~h}$ resulting in the formation of hybrid conjugates (scFv-p(DEGMA-co-MACYS)). After conjugation, these amphiphiles were kept at $30^{\circ} \mathrm{C}$ for $10 \mathrm{~min}$, leading to insolubility of the thermoresponsive chain. Subsequent centrifugation $(14,100 \mathrm{rcf}$ for $10 \mathrm{~min})$ led to precipitation and formation of a hybrid conjugate pellet, while unbound scFvs remained in the supernatant and could be removed. The pellet was then redispersed into PBS and centrifuged with Amicon ${ }^{\circledR}$ Spin filters (MWCO: $30 \mathrm{kDa}$ ) to remove any unbound polymer from the hybrid conjugate. The resulting hybrid conjugates were 
evaluated using HPLC analysis (Figure 3C), and the obtained result is consistent with successful antibody conjugation to the synthetic hydrophobe. ${ }^{25}$ Successful conjugation was further validated using sodium dodecyl sulfate-polyacrylamide gel electrophoresis (SDSPAGE) analysis (Figure S3), where the archetypical smearing of the conjugate (lane 4), rather than single sharp band as observed for the scFv alone (lane 2), was indicative of scFv coupling to the synthetic copolymer. The elongated and "smeared" peak was present in SDS PAGE for both Coomassie blue and Cy5 channels (labelling of both the protein and the polymer hydrophobe), further corroborating successful coupling. ${ }^{26,27}$

A)

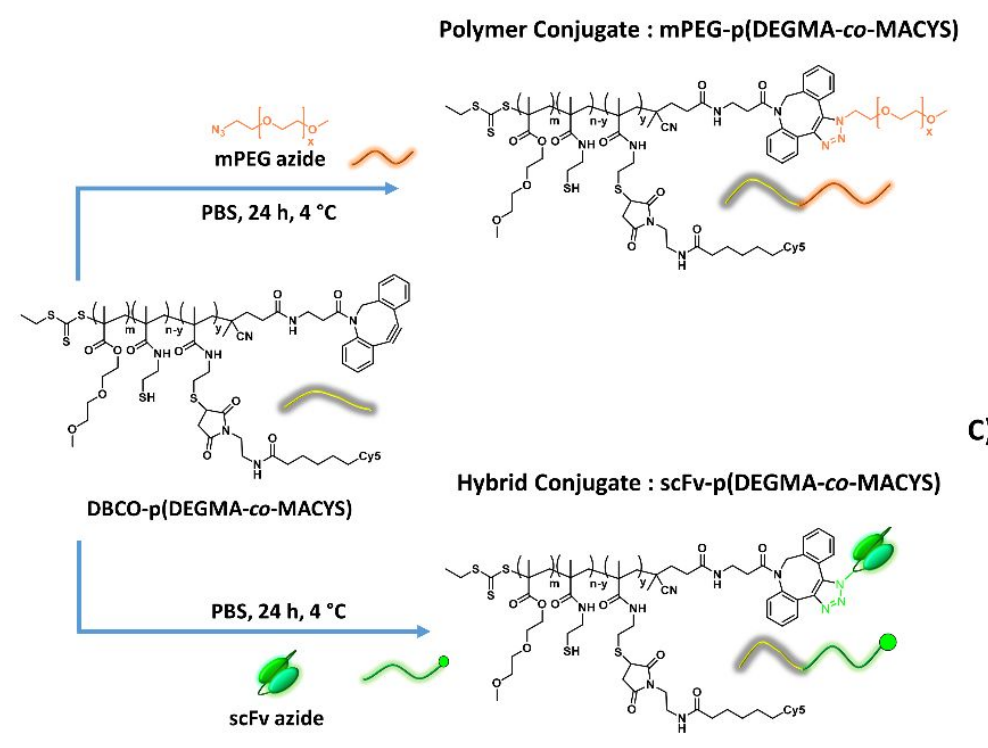

B)

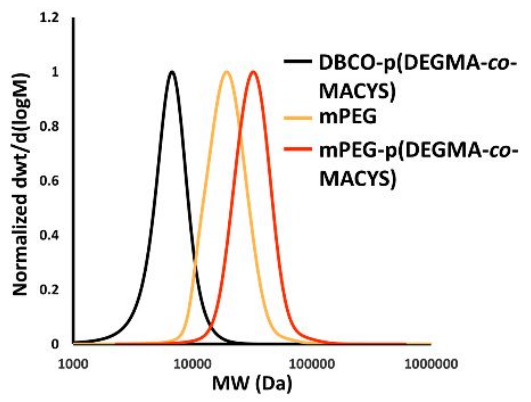

C)

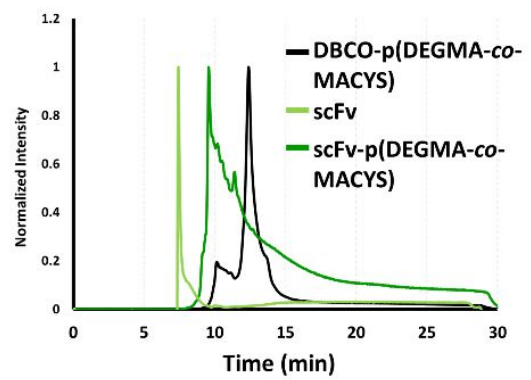

Figure 3. (A) Schematic representation of the structures of both the mPEG and scFv hybrid conjugates. (B) SEC chromatogram of the mPEG-polymer conjugate (red) along with starting materials, mPEG-N ${ }_{3}$ (orange) and DBCO-p(DEGMA-co-MACYS) polymer (black). (C) HPLC chromatogram of the hybrid conjugate (dark green) along with controls, J591 scFv- $\mathrm{N}_{3}$ (light green) and DBCO-p(DEGMA-co-MACYS) polymer (black).

A similar procedure was used to develop the polymer conjugate (mPEG-p(DEGMA-coMACYS)), in which DBCO-p(DEGMA-co-MACYS) was incubated with commercially- 
available methoxy-PEG (mPEG) azide in water at $4{ }^{\circ} \mathrm{C}$ for $24 \mathrm{~h}$. mPEG has been widely used to improve the therapeutic index of clinical drugs, ${ }^{28}$ and formulations such as mPEG modified liposomal doxorubicin (Doxil / Caelyx) are accepted by the Food and Drug Administration (FDA) for the treatment of breast cancer. ${ }^{29}$ In order to prevent recognition by the mononuclear phagocytic system (MPS) and thereby impart stealth properties to the micelles, mPEG displaying a radius of hydration $\left(\mathrm{R}_{\mathrm{H}}\right)$ of $4 \mathrm{~nm}$ similar to the $\mathrm{scFv}$ (Figure $\mathrm{S} 4$ ), was used to form mPEG conjugates, with successful coupling demonstrated by size exclusion chromatography (Figure 3B).

The cellular association of the monomeric conjugates with prostate cancer cells that had high (PC3-PIP cells: PSMA+) and low (PC3 cells: PSMA-) levels of PSMA expressions were assessed to demonstrate targeting ability of the conjugates ${ }^{30}$ Flow cytometry analysis of the conjugates following incubation at $4{ }^{\circ} \mathrm{C}$ (when the chains would be in their soluble form) showed significantly higher association for the hybrid conjugates in PSMA+ cells compared to the polymer conjugate (Figure S5). Likewise, in the cells that showed low expression of PSMA (PSMA-), much lower association was observed for both conjugates, indicating that the mechanism of association was likely via receptor-mediated interactions. Importantly, this preliminary in vitro study suggested that the coupling approach still facilitated successful presentation of the $\mathrm{scFv}$ for binding to the receptor.

Synthesis of micellar assemblies. Micelles were synthesised with varying antibody densities by mixing the amphiphilic hybrid conjugates with the polymer conjugates in PBS at temperatures below the $\operatorname{LCST}\left(16^{\circ} \mathrm{C}\right)$, then increasing the temperature above the LCST, whereupon the thermoresponsive behaviour of the hydrophobic component led to selfassembly of the conjugates. ${ }^{31}$ This process is reversible, and as an example for purely polymer conjugates or hybrid conjugates, Figure 4 shows the size by dynamic light scattering (DLS) of 
unimers (at $5{ }^{\circ} \mathrm{C}$ ), their assembly into micelles at $25{ }^{\circ} \mathrm{C}$, then subsequent destabilisation and existence of unimers when cooled back down to $5{ }^{\circ} \mathrm{C}$. Importantly, this process was observed to occur for both the polymer and hybrid conjugates, with the size of the micelles being approximately $70 \mathrm{~nm}$ at $25{ }^{\circ} \mathrm{C}$, irrespective of the hydrophile that was used, allowing for a decoupling of micelle size and composition; this was an important pre-requisite for future comparisons (Figure S6). In addition, the zeta potential of the micelles was found to be less affected by an increase in antibody density, with the overall charge remaining neutral independent of antibody density (Figure S7).

\section{Ao $\approx$ Polymer micelles}

\section{Before crosslinking}

\section{Hybrid micelles}

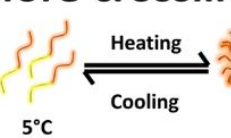

A)

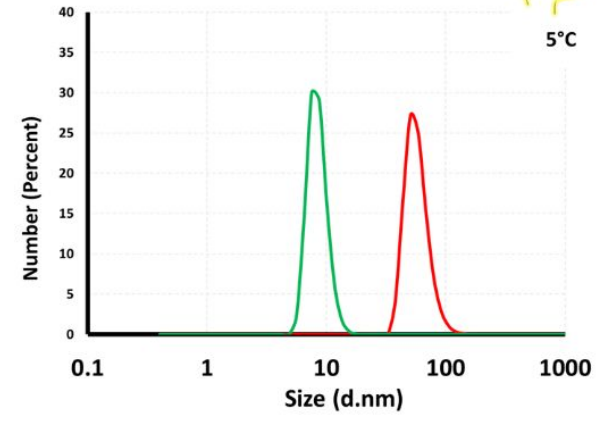

C)

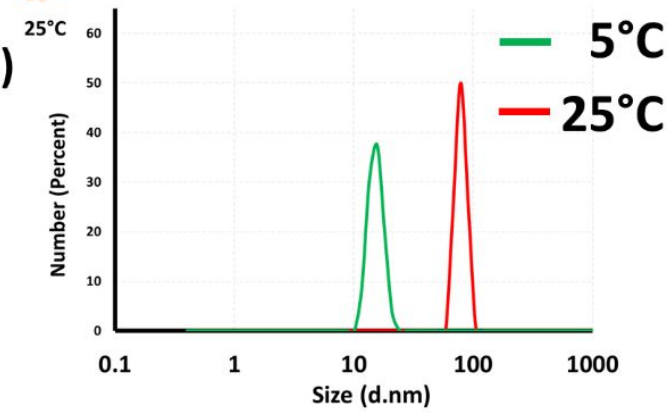

After crosslinking
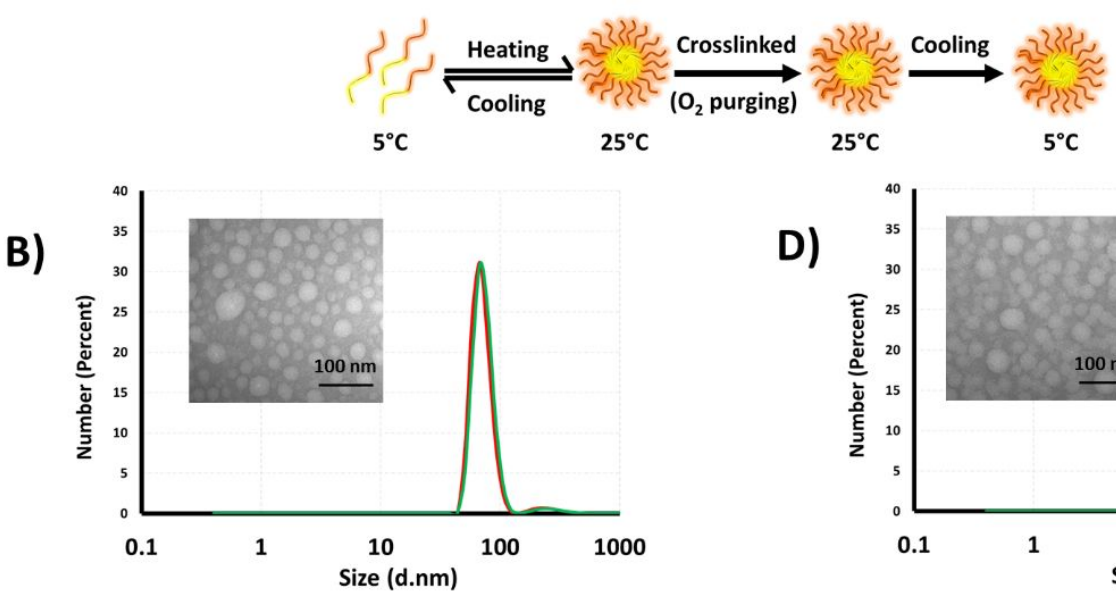

D)

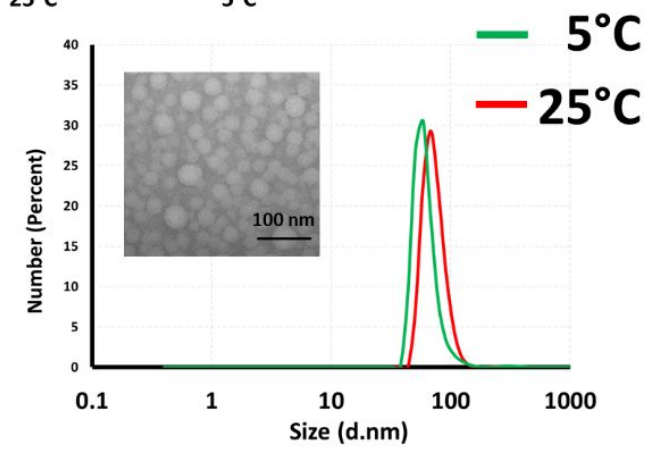


Figure 4. DLS size distribution of the micelles from polymer conjugate and hybrid conjugates. (A) non-crosslinked polymer micelles, (B) crosslinked polymer micelles by oxygen purging, (C) non-crosslinked hybrid micelles, and (D) crosslinked hybrid micelles at $25{ }^{\circ} \mathrm{C}$ (red) and 5 ${ }^{\circ} \mathrm{C}$ (green). The insert in 4B and 4D shows the TEM images of crosslinked micelles from polymer and hybrid conjugates respectively, indicating an average size of $70 \mathrm{~nm}$. Oxygen purging results in crosslinking due to the formation of disulfide bonds between the thiol groups of the CYS side-chains.

The micelles were synthesised by mixing the PEG and hybrid conjugates in varying ratios. In order to characterise the amount of antibody components in micelles, a secondary system was developed, in which the hybrid conjugates were labelled with Cy5 and the polymer conjugates were labelled with RhodamineB (Figure S8). The average PEG-antibody ratios for each system were calculated based on the relative fluorescence intensity of Cy5 (for antibody amphiphile) to RhodamineB (for polymer amphiphile) (Figure S9). The "theoretical" correction factor was calculated based on the feed ratio of antibody:polymer in the hybrids and was compared to the actual fluorescence that we determined using the fluorimeter (for the 4 formulations that had the highest fluorescence content, e.g. A100, A75, A50, A25) with $<5 \%$ difference between these two values. This implies that there were little or no quenching arising from intermolecular interactions in any of these micelle systems. In order to ensure that the micelles were stable under both in vitro and in vivo conditions, the assemblies were transiently crosslinked using disulfide chemistry. ${ }^{32}$ Crosslinking not only acts to lock in the structure of the low glass transition temperature hydrophobe (DEGMA) to prevent dynamic exchange of the individual micellar components but also ensures stability following intravenous (I.V.) injection, where this has been shown to significantly affect in vivo accumulation and biodistribution of nanomedicines. ${ }^{33,34}$ Here, the thiol-functional group in CYS acts as the crosslinking point by 
forming disulfide bonds by oxidation through oxygen purging. ${ }^{35,36}$ Evaluation of the size of the micelles following oxidation showed crosslinked micelles retained their size even after reducing the temperature to below the LCST, suggesting that the micelles were locked in conformation (Figure 4B and 4D). TEM micrographs of both micelles are also shown in Figure 4 (inset), confirming the size of the assemblies formed. The stability of purely synthetic micelles was further analysed in cell culture media containing foetal bovine serum (FBS) as pseudo-serum conditions, and the structures maintained integrity and size over $24 \mathrm{~h}$ (Figure S10). However, longer incubation of these micelles in 50\% serum-containing media resulted in an increase in micelle size, most likely due to higher serum protein interactions (Figure S11). Importantly, there was no evidence of degradation of the micelles through observation of small fragments in the DLS. Moreover, fluorescence stability of A0 micelles showed $<15 \%$ Cy5 loss in 50\% FBS media for an incubation of $48 \mathrm{~h}$ (Figure S12). The crosslinking of the micelles offers greater control over the material used for in vivo experiments and provides confidence that the interactions observed are due to micellar interactions, rather than interactions by fragments of the micelles.

Effect of ligand density on cellular association and internalisation. Micelles of varying scFv densities $(0,5,10,15,25,50,75,100 \%$ chain ratio relative to the PEG-hydrophile) were assembled to investigate the relationship between antibody density and cellular association and were labelled as A0, A5, A10, A15, A25, A50, A75, and A100, respectively (Figure 1). These micelles were incubated with prostate cancer cell lines that either had high expression of PSMA (PSMA+) or low expression (PSMA-) for $1 \mathrm{~h}$ prior to evaluation of cell binding by flow cytometry ${ }^{30}$ Cellular association studies using flow cytometry demonstrated that even with a small increase in antibody density, micelles typically showed an increased association with PSMA+ cells. For these cells that upregulated PSMA, the cellular association was seen to rise 
with increasing antibody content until reaching a plateau at $25-50 \%$ incorporation of antibody, before decreasing modestly at higher incorporation (Figure 5A). This may be due to the potential for receptor saturation, resulting from the interaction between higher amounts of scFvs with the PSMA receptors on the particular cell line. In addition to receptor saturation, the decrease in nanoparticle association might also be due to the competitive binding between micelles onto the receptors. ${ }^{37,38}$ Compared to $50 \%$ antibody micelles, $100 \%$ micelles have higher antibody content resulting in higher competition for interacting with the active site of the receptors, thereby hindering the cellular association. ${ }^{39-41}$ The association with PSMA- cells was low, indicating that specific interaction was negligible with receptors on this cell line. This has been further validated using a competition assay, where the PSMA+ cells exhibited significantly reduced cellular association with the targeted micelles when pre-incubated with free $\operatorname{scFv}\left(10 \mu \mathrm{g} \mathrm{mL}^{-1}\right)$, compared to when treated with targeted micelles alone (Figure S13). To better understand the observed trend in receptor binding on PSMA+ cells, a binding assay was conducted to explore the effect of different concentrations of antibody containing micelles (A25 and A100) (Figure S14) on cellular association. Under these conditions, the number of micelles at each concentration were approximately the same for A25 and A100. A100 was found to bind to maximum number of cells (\% cell association) at a lower concentration than A25 $(25 \mu \mathrm{g} / \mathrm{mL}$ compared to $100 \mu \mathrm{g} / \mathrm{mL}$, respectively), potentially due to the avidity effect of these nanoparticles (more antibodies to bind with receptors). And when both A25 and A100 showed association with $100 \%$ of cells $(100 \mu \mathrm{g} / \mathrm{mL})$, the MFI was higher for A25 than A100. This suggests that at high concentrations, more of the nanoparticles with lower antibody density can bind to the cells than those with higher antibody density. Therefore, these changes in cellular association might be due to combination of multiple factors including receptor clustering, ${ }^{42}$ receptor crowding by high antibody density nanoparticles ${ }^{43}$ or steric crowding of 
the antibody on the nanoparticles ${ }^{44}$ which ultimately leads to difference in the association levels in vitro. ${ }^{45,46}$

Interaction of a subset of the micelles (A0, A25, and A100) with both PSMA+ and PSMAcells was evaluated by confocal microscopy in order to assess the effect of antibody on the degree of cell internalisation. The microscopy showed a similar trend to that observed in the flow cytometry, whereby higher uptake is observed for the A25 micelle than either the A0 or A100 micelle, again pointing at a receptor-mediated interaction that is modulated by ligand density (Figure 5B).

A)

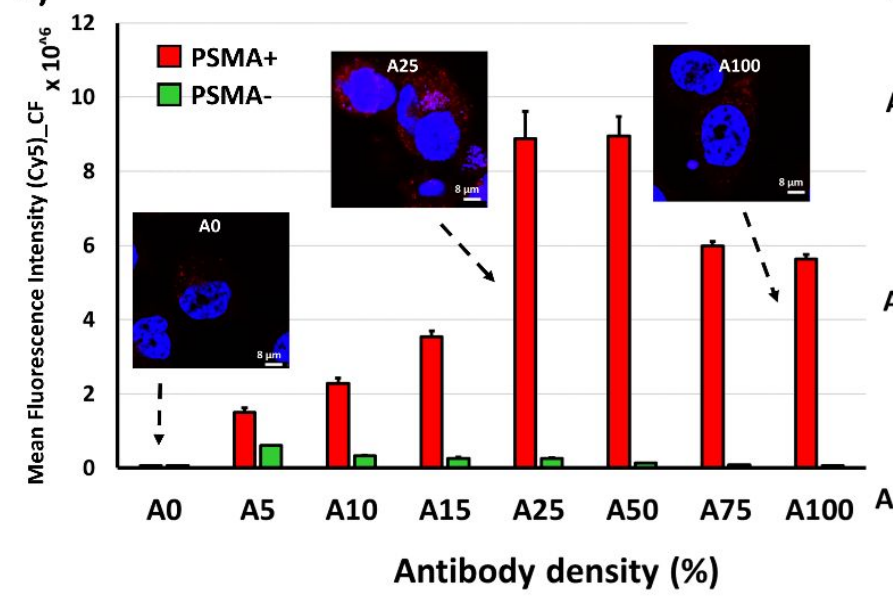

B) Hoechst 33342
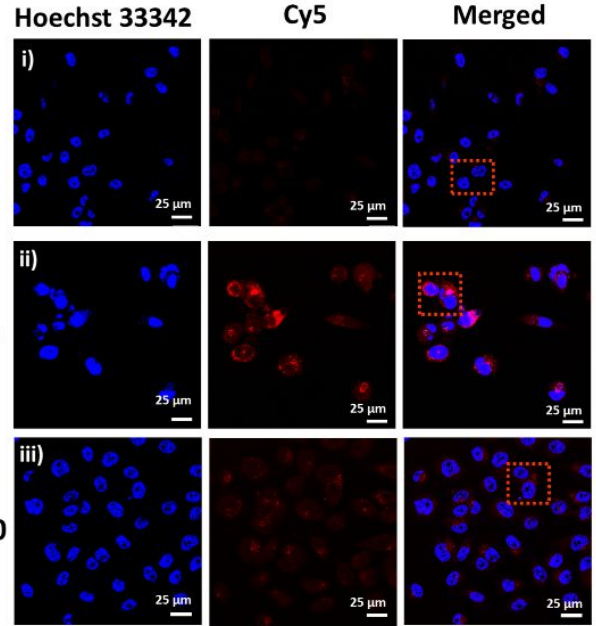

Figure 5. (A) Flow cytometry analysis of PSMA+ and PSMA- cells association of Cy5 labelled micelles with varying antibody densities $(0,5,10,15,25,50,75$, and 100\%). (B) Confocal microscopy images of PSMA+ cells incubated with micelles of varying antibody densities $(0$, 25 and 100\%), along with magnified confocal images showing the distribution of micelles across the PSMA+ cells.

Biodistribution and tumour accumulation of micelles with varying antibody densities in tumour-bearing mice. The influence of ligand density on in vivo biodistribution and tumour accumulation was evaluated to understand the balance between increased cell targeting (with increasing ligand density) and tumour accumulation. BALB/c nude mice bearing both 
(PSMA+) and (PSMA-) prostate cancer xenografts in their opposite flanks were administered micelles with varying antibody densities through I.V. injection. Mice were sacrificed and organ distribution of the Cy5-labelled micelles monitored by fluorescence imaging ( 24 and $48 \mathrm{~h}$ ). In order to compare the micelles between tumour bearing mice, the fluorescence intensities were normalised with respect to the $100 \%$ antibody containing micelles, which has been accounted for in Table S1. At $24 \mathrm{~h}$ post-injection, the PSMA+ tumours demonstrated an antibodydependent micelle accumulation, showing an almost 19-fold increase in micelle accumulation with the increase of antibody density from $0 \%$ to $25 \%$, owing to enhanced retention in the tumour (Figure 6A). However, increasing the antibody content further resulted in a decreasing level of tumour accumulation compared to A25, with A50, A75 and A100 micelles only achieving a doubling of micelle accumulation compared to A0. This decrease in accumulation above A25 was most likely caused by a decreased concentration of circulating micelles due to immune recognition of the more proteinaceous nanomaterials. Such an effect ultimately leads to the clearance by the mononuclear phagocytic organs such as liver and spleen. This scenario was confirmed by the increase in fluorescence in these organs with increasing antibody content (Figure 6B), thereby resulting in a decrease in overall circulating micelle content in the blood and consequently decreased accumulation in the tumour at longer time points. At $24 \mathrm{~h}$ postinjection, the PSMA- tumour showed significantly less micelle accumulation in the tumour at all antibody compositions and similar to that observed for A0 (in both tumours), suggesting that the presence of antibody (even in the A100 sample) contributes to improvement in tumour tissue accumulation above that observed by the enhanced permeability and retention (EPR) effect alone. ${ }^{47}$ 
A)

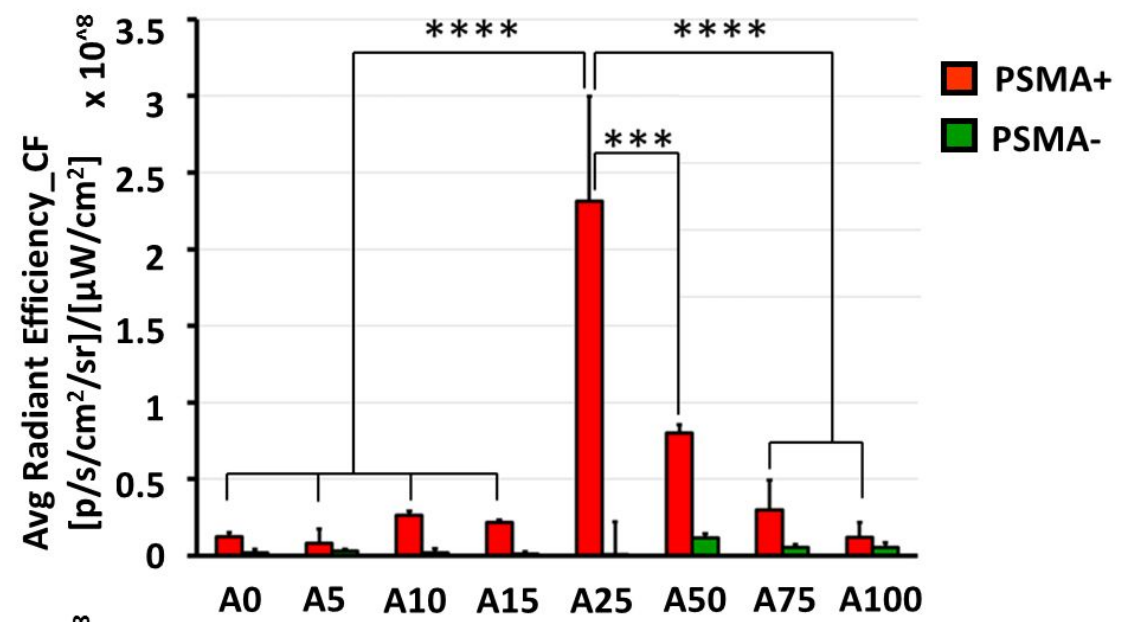

B)

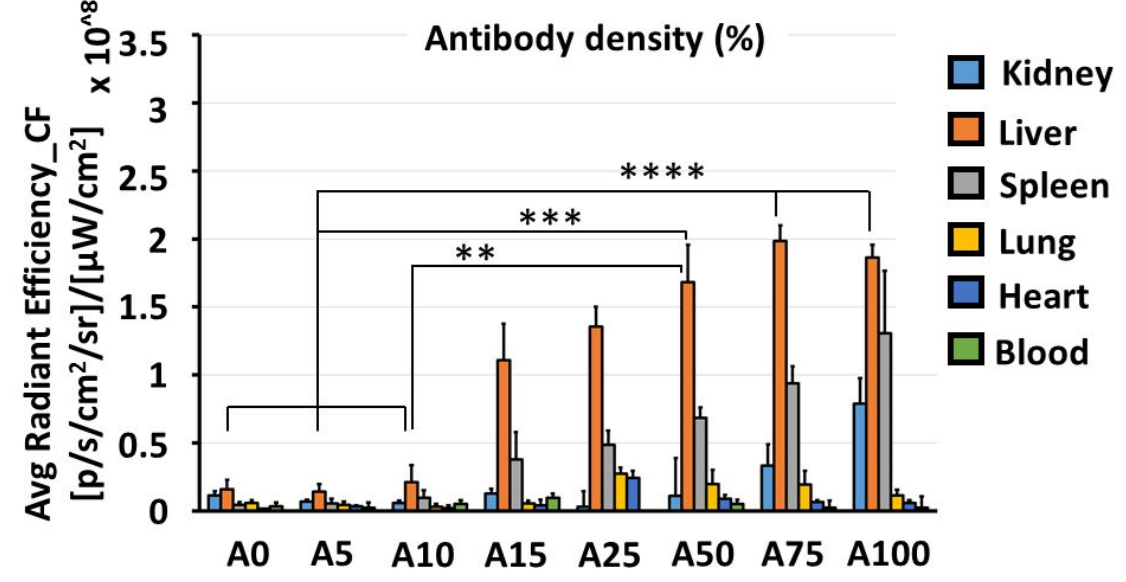

C)

Antibody density (\%)
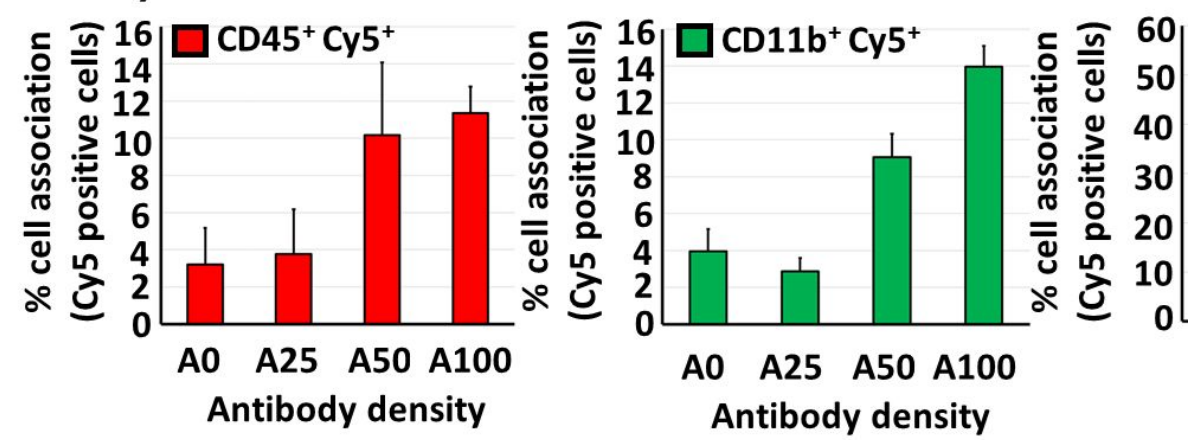

$\square \mathrm{F} / 80^{+} \mathrm{Cy}^{+}$

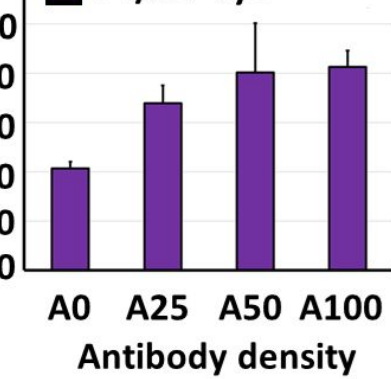

Figure 6. (A) Bar chart showing the average radiant efficiency of Cy5 signals from PSMA+ and PSMA- tumour, $24 \mathrm{~h}$ post-I.V. injection of micelles with varying ligand densities of 0,5 , $10,15,25,50,75,100 \%$ antibody content. (B) Bar chart showing the average radiant efficiency of Cy5 signals from other major organs, $24 \mathrm{~h}$ post-I.V. injection of micelles with varying ligand densities of $0,5,10,15,25,50,75,100 \%$ antibody content. (C) Bar chart showing the cellular association of micelles with immune cells such as leukocytes $\left(\mathrm{CD} 45^{+}\right)$, monocytes $\left(\mathrm{CD} 11 \mathrm{~b}^{+}\right)$ 
and macrophages $\left(\mathrm{F} 4 / 80^{+}\right)$in the liver after $24 \mathrm{~h}$ post-I.V. injection of micelles with varying ligand densities of $0,25,50$, and $100 \%$ antibody content. ( $n=3$ per group), $(* *=\mathrm{p}<0.01, * * *$ $=\mathrm{p}<0.001, * * * *=\mathrm{p}<0.0001)$.

A similar trend in accumulation is observed at $48 \mathrm{~h}$, where the effect of passive targeting (to PSMA-) was slightly more prominent than the $24 \mathrm{~h}$ time point (Figure S15).

Micelle association with murine immune cell populations. The ratio of PEG to antibody component on the surface of the micelles has a significant impact on its accumulation and distribution across tumour and other organs. It is crucial to understand the influence of antibody density on the interactions between micelles and immune cells, predominantly present in the liver and spleen for nanoparticles. These immune cells constitute the MPS, and upon stimulation results in rapid clearance of micelles from animals. We established a flow cytometric assay to furnish important insights into micelle distribution between different immune cell types in liver and spleen following injection of the micelles into immunocompetent mice (Figure 6C, S16 and S17). The use of a CD45 marker (to identify immune populations from other cell types in the organ), as well as a live/dead exclusion dye, provided a useful means to investigate immune-trafficking of the micellar particles. In terms of gating strategy, after identifying the immune cells $\left(\mathrm{CD}^{4} 5^{+}\right)$from the whole cell population, additional markers such as $\mathrm{CD} 11 \mathrm{~b}$ and F4/80 were used to distinguish monocytes and macrophage subpopulations, respectively. The flow cytometry suggested a 3-fold higher proportion of A100 micelles in whole immune cell $\left(\mathrm{CD}^{4} 5^{+}\right)$populations compared to the A0 micelles (Figure 6C). The CD11 $\mathrm{b}^{+}$cell population includes monocytes, a subset of white blood cells that play a key role in homeostasis and inflammation, and can be readily transported to the site of inflammation. ${ }^{48}$ In the $\mathrm{CD} 11 \mathrm{~b}^{+}$cell population in liver and spleen, the association was three- to eight-fold higher for hybrid micelles compared to polymer micelles, with 
increasing association with greater antibody content. We also observed higher cellular association for F4/80+ macrophages in the case of A100 micelles. Generally, Kupffer cells and splenic red pulp macrophages show high levels of expression for F4/80 glycoprotein and have critical roles in immune surveillance, with Kupffer cells being the major route of nanoparticle removal from circulation. ${ }^{49,50}$ The increased immune response for A100 micelles with an increase in antibody content clearly indicates an active role of the immune system in recognising, and clearing these micelles from circulation. After I.V. injection of micelles, serum proteins in the blood binds to these micelles resulting in a protein corona. ${ }^{51-54}$ This binding depends on the surface properties of the micelles; for instance, PEGylation blocks the serum protein interaction resulting in lower MPS recognition. However, the presence of antibodies on the micelle surface triggers the serum protein interaction and thereby results in enhanced liver and spleen clearance. To exemplify this point, interactions between micelles and serum proteins were studied by incubating them in FBS containing cell culture media. In this experiment, the serum protein interaction was significant only for an antibody content of $50 \%$ or higher (Figure S18) in the micelles. Furthermore, an evaluation of the micelle distribution in various immune cells in mice blood ex vivo was also carried out. In general, the higher the antibody content in the micelle, the greater the interaction with all elements of the immune cell populations that we investigated. Moreover, more specific association with blood immune cell populations, including neutrophils and monocytes, was observed at higher antibody concentrations (Figure S19).

Micelle accumulation in human white blood cells. A key issue in the translation of nanomedicines to clinical acceptance is the mismatch between observations in mouse and human studies. With this in mind, we next investigated the micellar association with the immune population of cells in whole human blood, as these will be the first host cells that 
interact with micelles following I.V. administration. ${ }^{55}$ Human blood immune cells such as granulocytes (mainly neutrophils), monocytes, lymphocytes (B-cell and T cell) and dendritic cells were analysed after incubation with the micelles with fresh whole human blood for $1 \mathrm{~h}$ at $37^{\circ} \mathrm{C}$ using established methodologies previously reported by Kent et al. ${ }^{56}$ Overall, there was a clear modulation in immune-cell interaction as a result of increasing antibody content in the micelles. Association was highest for A100 and A75 micelles with granulocytes, with approximately $80-90 \%$ cells showing some interaction with the micelles (Figure 7A). While A50 micelles showed $40 \%$ association, further lowering of antibody content showed minimal association. This observation clearly shows immune recognition resulting from the interaction of antibody component with neutrophils and its phagocytic nature. ${ }^{55}$ Within the monocyte population, A0 micelles showed less than $1 \%$ cellular association indicating its stealth nature, a direct consequence of the purely PEG surface nature of this particular micelle. However, $10 \%$ or higher antibody content showed an increase in cellular association with $>10 \%$ of cells showing a measurable association when the antibody component of the micelles was $50 \%$ (Figure 7B). Similar trends were observed for both lymphocyte populations and dendritic cells (gating strategy used for differentiating cell populations are shown in Figure S20). These results showed a direct link between the level of antibody density and immune-cell interaction, with an enhanced immune clearance of the micelles with $\geq 50 \%$ antibody content. These human ex vivo blood studies are precisely comparable to our in vivo mouse studies above, suggesting that the findings are likely to be transferable (at least in the broadest sense) to clinical assessment of nanomedicines. More importantly, these in-depth immune studies offer some important insight into why greater antibody density often leads to a mismatch between in vitro cancer cell association studies (undertaken extensively in vitro in nanomedicine research) and tumour accumulation and/or efficacy studies of nanotherapeutics. ${ }^{9}$ It is clear that each 
nanomedicine needs to be assessed on a case-by-case basis, where the merit of targeting specific receptors present on cells is weighed against the need for stealthiness.

It is also important to consider the effects of multiple copies of a targeting agent on the cell surface and intracellular processing pathways more generally. Pattern recognition by the immune system is an important mechanism in the body's defence against pathogens, particularly viruses which display multiple ligands in order to take advantage of multivalent interactions. Accordingly, the use of repeating patterns of protein recognition domains on a synthetic nanoparticle might be expected to result in increased detection by immune surveillance mechanisms. In addition, it has been shown that engagement of multiple receptors at some cancer cell surfaces can lead to clustering and changes in intracellular trafficking pathways leading to lysosomal accumulation. ${ }^{12,14}$ This might be detrimental for delivery of biotherapeutics but advantageous for lysosomally-activated pro-drugs. Therefore, it may be the case that an optimal targeting ligand density exists and that this will depend on the route of administration, the immune status of the patient, and the specific disease site and therapeutic agent. The results in this study provide important design criteria which might allow future optimisation and ultimately personalisation of nanomedicines. 


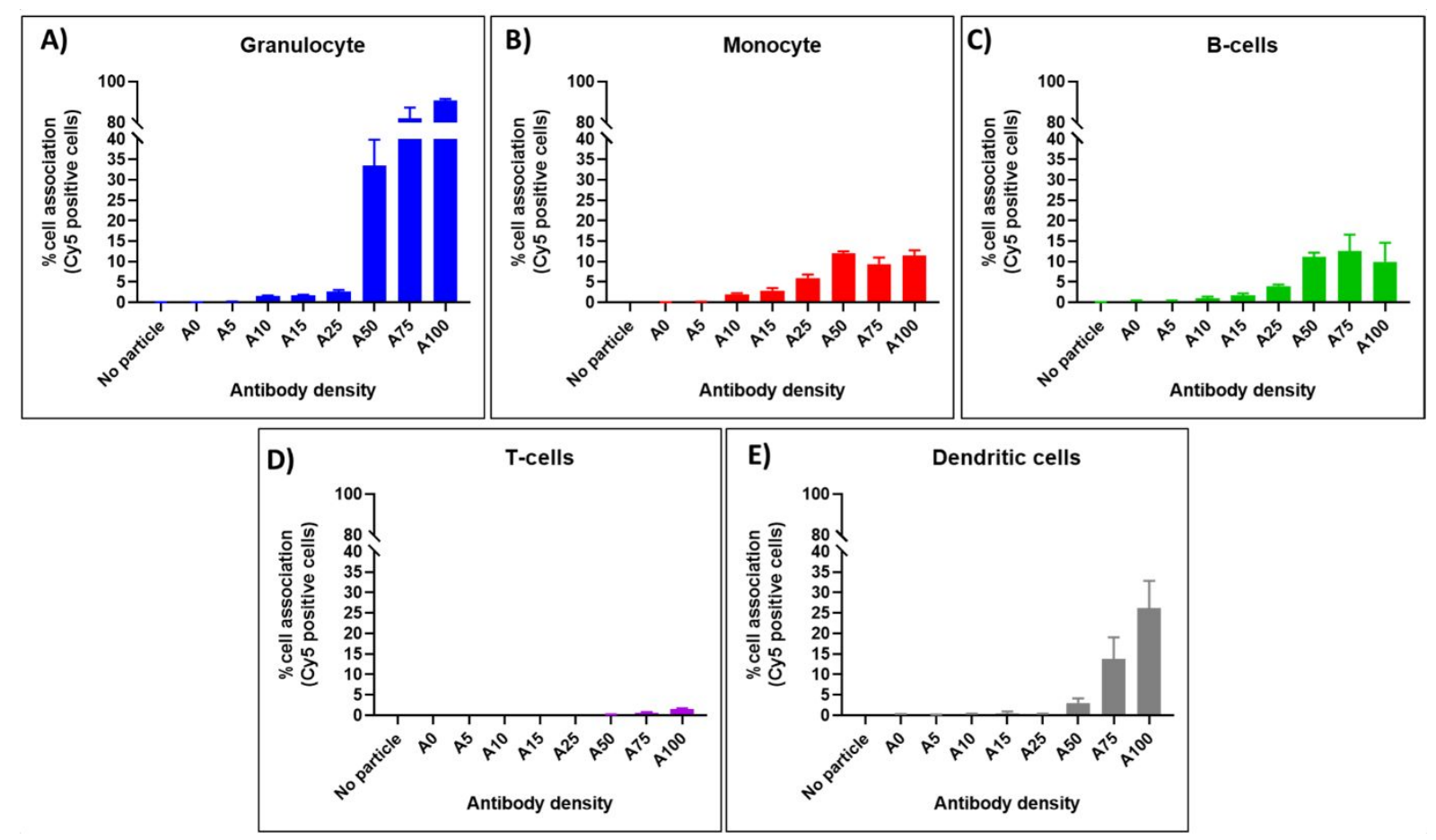

Figure 7. Effect of antibody density on the interaction of micelles with human innate immune cells. Histograms show the percentage cellular association of micelles with (A) Granulocytes, (B) Monocytes, (C) B-cells, (D) T-cells, (E) Dendritic cells at $37^{\circ} \mathrm{C}$.

\section{CONCLUSION}

We report an approach to generate a micellar nanomaterial platform with control over antibody fragment surface density, allowing us to study in-depth the true influence of surface functionalisation on both cell binding, immune recognition and tumour accumulation of nanomedicines. The micellar assemblies showed antibody-density dependent association and internalisation in cells that upregulate a receptor that binds to the antibody (PSMA receptor), with maximum association observed between $25-50 \%$ antibody surface density. The decrease in association at higher densities was attributed to receptor saturation or potentially clustering effects of the receptor on the cell surface. Moreover, when administered intravenously into tumour-bearing mice, significantly enhanced tumour association was observed for the micelle with $25 \%$ antibody density compared to all other densities. The decrease in accumulation at a 
higher density above $25 \%$ was shown to be proportional to the increase in immune recognition of these species and subsequent clearance through the MPS organs. The micelles clearly become less "stealthy" in mice with greater antibody content, which was also confirmed by our ex vivo human whole blood analyses. Additionally, our studies on human white blood cells demonstrated that the higher antibody densities had an influence on immune cell interactions. These results provide an understanding of how these fundamental properties of designed nanoparticles can be utilised to enhance cellular uptake, and influence biodistribution in animals, and later into clinical settings. Moreover, it is clear that there is at least a broad level of agreement between mouse immune studies and the human case, suggesting translatability of these observations when designing nanomedicines for human use. In the cancer nanomedicine field, it is becoming increasingly clear that just delivering the payload to the target is not enough but now requires an in-depth understanding of the collateral damage these nanomaterials could have to healthy immune cells. Ultimately, accessing the "sweet spot" in terms of increasing cell-association/internalisation through increased antibody density (often a necessity for delivery of specific drugs, such as biologics), and minimising immune recognition by maintaining stealthiness, are now key attributes for developing next-generation targeted nanomedicines that could offer improved clinical outcomes.

\section{EXPERIMENTAL}

\section{Materials}

Dibenzocyclooctyne-amine (DBCO, Sigma-Aldrich, $\geq 94.5 \%)$, triethylamine $\left(\mathrm{Et}_{3} \mathrm{~N}\right.$, SigmaAldrich, $\geq 99 \%$ ), 2,2'-azobis(isobutyronitrile) (AIBN, Sigma-Aldrich, 98\%), 1-ethyl-3-(3dimethylaminopropyl) carbodiimide hydrochloride (EDC, Fluorochem, 99\%), Nhydroxysuccinimide (NHS, Sigma-Aldrich, 98\%), cysteamine hydrochloride (CYS, Sigma- 
Aldrich, $\geq 98 \%$ ), methoxy-PEG-azide $\left(\mathrm{M}_{\mathrm{n}}=20 \mathrm{kDa}\right)$ (mPEG, Biochempeg, $\left.\geq 95 \%\right)$, Cyanine5 maleimide (Cy5, Lumiprobe, > 95\%), phosphate-buffered saline (PBS, Astral scientific) were all used as received. Solvents including $N, N$-dimethyl-formamide (DMF), 1,4-dioxane, methanol, tetrahydrofuran (THF), $n$-hexane, and dichloromethane $\left(\mathrm{CH}_{2} \mathrm{Cl}_{2}\right)$ were used dry where applicable and of reagent grade quality. Diethylene glycol methacrylate (DEGMA, Sigma-Aldrich, 98\%) were passed through basic alumina to remove inhibitor before use. MilliQ water $\left(18.2 \mathrm{~m} \Omega \cdot \mathrm{cm}^{-1}\right.$ at $\left.25{ }^{\circ} \mathrm{C}\right)$ was used throughout. Pentafluorophenyl methacrylate (MAPFP) was synthesised according to Fuchs et al.. ${ }^{57}$ RAFT agent 4-Cyano-4(ethylsulfanylthiocarbonyl) sulfanylpentanoic acid (CEPA) was synthesised according to Convertine et al. ${ }^{58}$ Dimethyl sulfoxide- $\mathrm{d}_{6}\left(\mathrm{DMSO}-\mathrm{d}_{6}\right)$, deuterated chloroform $\left(\mathrm{CDCl}_{3}\right)$ were purchased from Cambridge Isotope Laboratories, Inc. Cell culture medium Roswell Park Memorial Institute (RPMI) 1640, foetal bovine serum (FBS), were purchased from Life Technologies, Mulgrave, Vic, Australia and Moregate, Brisbane, Australia respectively. Penicillin/streptomycin mix, trypsin, trypan blue solution and Hoescht 33342 were obtained from Sigma-Aldrich. Prostate cancer cells (PC3-PIP (PSMA+) and PC3 (PSMA-) cells were received from Dr Warren Heston. ${ }^{59}$ Tissue culture treated imaging $\mu$-dishes with 1.5 NA coverslips were ordered from ibidi ${ }^{\mathrm{TM}}$.

\section{Methods}

All nanomaterials were characterised using standardised reporting methods recommended by Faria et al., where applicable. ${ }^{60}{ }^{1} \mathrm{H}$ nuclear magnetic resonance (NMR), ${ }^{19} \mathrm{~F}$ NMR spectra were measured on Bruker AC 400 or $500 \mathrm{MHz}$ spectrometers in $\mathrm{CDCl}_{3}$ or $\mathrm{DMSO}-\mathrm{d}_{6}$ at $25{ }^{\circ} \mathrm{C}$. 
Size exclusion chromatography (SEC) for analysis of polymer molecular weight and dispersity was performed on a system consisting of a 1515 Isocratic pump (Waters), a 717 autosampler (Waters), Styragel HT 6E and Styragel HT 3 columns (Waters), a 2414 differential refractive index detector (Waters). THF was used as the mobile phase at a flow rate of $1 \mathrm{~mL} \mathrm{~min}^{-1}$ and polystyrene (PS) as the standards. Empower 2 (Waters) software was used for data collection and processing. All samples were freshly prepared before analysis and filtered through a 0.45 $\mu \mathrm{m}$ filter to eliminate large particulates. The hydrodynamic diameters and zeta potentials of micelles were explored on a Nanoseries Zetasizer (Malvern 90, UK). The samples were analysed at a scattering angle of $90^{\circ}$ and two different temperatures 278 and $298 \mathrm{~K}$, respectively. Samples were filtered through $0.45 \mu \mathrm{m}$ PTFE filters prior to measurement. UVVis measurements were performed on a Nanodrop 2000C spectrophotometer (Thermo Scientific) using a low volume $(700 \mu \mathrm{L})$ quartz cuvette with a $10 \mathrm{~mm}$ path length. Absorbance maxima were recorded at 309 and $647 \mathrm{~nm}$ for $\mathrm{DBCO}$ and $\mathrm{Cy} 5$ absorbance respectively. For transmission electron microscope (TEM) imaging, particles were dissolved in water, dropped onto copper grids, and air-dried before imaging. Polyacrylamide gel electrophoresis (PAGE) was performed on Bolt ${ }^{\mathrm{TM}}$ 4-12\% Bis-Tris Plus Gels (Invitrogen, Paisley, UK) equipped with a PowerPac Basic power supply at $200 \mathrm{~V}$ for $30 \mathrm{~min}$ in $1 \mathrm{X}$ NuPAGE® MES SDS Running Buffer . The visualisation of the Coomassie blue-stained gels was carried out on a ChemiDoc Imaging system, Bio-Rad. High-performance liquid chromatography (HPLC) was performed on Dionex HPLC-Thermo TSQ Quantum Ultra QqQ MS couple equipped with UV-visible detector and a reverse-phase $\mathrm{C}_{18}$ column $(75 \times 4.6 \mathrm{~mm})$. Gradient elution from 95\% Milli-Q water containing $0.2 \%$ formic acid to $100 \% \mathrm{MeCN}: \mathrm{H}_{2} \mathrm{O}(8: 2)$ with $0.2 \%$ formic acid over a time period of 30 min with a $200 \mu \mathrm{L} \mathrm{min}{ }^{-1}$ flow rate was used throughout. The wavelengths of $280 \mathrm{~nm}$ and 647 $\mathrm{nm}$ were used for the detection of antibody and conjugates respectively for the analysis. 
Cell culture. Two human prostate cancer cell lines (PC3-PIP (PSMA+) and PC3 (PSMA-) were maintained in RPMI medium supplemented with 10\% (v/v) FBS (heat-inactivated, Bovogen), $100 \mathrm{U} \mathrm{mL}^{-1}$ penicillin, $100 \mu \mathrm{g} \mathrm{mL}^{-1}$ Streptomycin and $2 \mathrm{mM}$ L-glutamine and incubated at $37{ }^{\circ} \mathrm{C}$ in a humidified atmosphere of $5 \% \mathrm{CO}_{2}$ in air.

Synthesis of p(DEGMA-co-MAPFP) copolymer using CEPA. DEGMA (0.3 g, 1.59 mmol), MAPFP (45 mg, $0.18 \mathrm{mmol}), \operatorname{AIBN}\left(1.1 \mathrm{mg}, 6.89 \times 10^{-3} \mathrm{mmol}\right)$, CEPA $\left(9.1 \mathrm{mg}, 3.44 \times 10^{-2}\right.$ mmol) and $660 \mu \mathrm{L}$ dry 1,4-dioxane were placed in a Schlenk tube equipped with a magnetic stirrer bar. The vial was sealed with a rubber septum, and the reaction mixture was sparged with nitrogen for $15 \mathrm{~min}$. The Schlenk tube was then placed in an oil bath and stirred at $65{ }^{\circ} \mathrm{C}$ for $18 \mathrm{~h}$. At the completion of the reaction, the polymer was precipitated dropwise into an excess of $n$-hexane three times. Once the polymer had fully settled on the bottom of the beaker, the solvent was decanted from the top, and the oily residue was dried in the vacuum oven. The purified p(DEGMA-co-MAPFP) was characterised using ${ }^{1} \mathrm{H}$ NMR (500 $\left.\mathrm{MHz}, \mathrm{CDCl}_{3}\right)$ and SEC.

Modification of p(DEGMA-co-MAPFP) copolymer with CYS. The pentafluorophenyl esters were replaced by adding 20 eq. of CYS (46 mg, $0.454 \mu \mathrm{M})$ and 20 eq. of $\mathrm{Et}_{3} \mathrm{~N}(35 \mathrm{mg}$, $0.45 \mu \mathrm{M})$ to $\mathrm{p}$ (DEGMA-co-MAPFP) copolymer $(150 \mathrm{mg}, 0.022 \mu \mathrm{M})$ dissolved in DMF. The solution was stirred at $50{ }^{\circ} \mathrm{C}$ for $24 \mathrm{~h}$. The reaction was cooled to room temperature, and DMF was removed in vacuo. The concentrated sample was redissolved in THF and purified by precipitating the polymer dropwise into an excess of $n$-hexane. The purified p(DEGMA-coMACYS) was dried under vacuum for $24 \mathrm{~h}$. These polymers were characterised using ${ }^{19} \mathrm{~F}$ NMR $\left(500 \mathrm{MHz}, \mathrm{CDCl}_{3}\right)$ and SEC. The LCST behaviour of polymer samples after CYS modification were determined using a UV-vis spectrophotometer set at $500 \mathrm{~nm}$. The polymeric samples were maintained at a concentration of $1 \mathrm{mg} \mathrm{mL}^{-1}$ in water and the solutions were heated from 
low temperatures to high temperatures at a heating rate of $1{ }^{\circ} \mathrm{C} \mathrm{min}-1$. The temperature at which $90 \%$ of the transmittance of the solution was observed was defined as the LCST.

Modification p(DEGMA-co-MACYS) copolymer with DBCO-amine. p(DEGMA-coMACYS) copolymer (150 mg, $27.5 \mu \mathrm{M})$ was activated by NHS (3.5 mg, $30 \mu \mathrm{M})$ and EDC $(10.5 \mathrm{mg}, 55 \mu \mathrm{M})$ (molar ratio of Polymer: $\mathrm{EDC}$ : $\mathrm{NHS}=1: 2: 1.1)$ in $\mathrm{CH}_{2} \mathrm{Cl}_{2}$ at room temperature overnight. DBCO-amine (7.6 mg, $27.5 \mu \mathrm{M})$ with $\mathrm{Et}_{3} \mathrm{~N}(3 \mathrm{mg}, 30.3 \mu \mathrm{M})$ was added and stirred for $12 \mathrm{~h}$. DCM was removed by rotary evaporation at room temperature, and the product DBCO-p(DEGMA-co-MACYS) was redissolved in THF and precipitated into $n$-hexane. The purified DBCO-p(DEGMA-co-MACYS) was dried under vacuum for $24 \mathrm{~h}$ and characterised using ${ }^{1} \mathrm{H}$ NMR (500 MHz, DMSO-d 6 ), SEC and UV analysis

Conjugation of DBCO-p(DEGMA-co-MACYS) with Cy5 maleimide. DBCO-p(DEGMAco-MACYS) copolymer $(150 \mathrm{mg}, 21.7 \mu \mathrm{M})$ was reacted with Cy5 maleimide $(1.4 \mathrm{mg}, 2.17$ $\mu \mathrm{M}$ ) in $\mathrm{CH}_{2} \mathrm{Cl}_{2}$ at room temperature for $12 \mathrm{~h}$. DCM was removed by rotary evaporation at room temperature, and the product was redissolved in THF and precipitated into $n$-hexane. The purified DBCO-p(DEGMA-co-MACYS) with Cy5 maleimide was dried under vacuum for 24 $\mathrm{h}$ and characterised using UV analysis.

Conjugation of DBCO-p(DEGMA-co-MACYS) with scFv azide. Before the conjugation reaction, DBCO-p(DEGMA-co-MACYS) copolymer was dissolved in PBS and kept for stirring at $4{ }^{\circ} \mathrm{C}$ for $1 \mathrm{~h}$. Then, the azide-functional $\mathrm{scFv}$ was added to the DBCO-p(DEGMAco-MACYS) copolymer solution, and the mixture was allowed to react at $4{ }^{\circ} \mathrm{C}$ for $24 \mathrm{~h}$. For a typical preparation, $5 \mathrm{mg}$ of DBCO-p(DEGMA-co-MACYS $)$ copolymer $(0.72 \mu \mathrm{mol})$ and 0.89 $\mu \mathrm{g}$ of $\mathrm{scFv}\left(3.5 \times 10^{-2} \mu \mathrm{mol}\right)$ were used (Polymer to $\mathrm{scFv}$ azide ratio of $\left.\sim 20: 1\right)$. After conjugation, samples were heated to temperature above LCST, $30{ }^{\circ} \mathrm{C}$ for $10 \mathrm{~min}$, which made the polymer insoluble. Upon centrifugation $(14,100 \mathrm{rcf}$ for $10 \mathrm{~min})$ the hybrid conjugate formed 
a pellet, and unreacted $\mathrm{scFv}$ remained in the supernatant. This pellet was redissolved in PBS at $4{ }^{\circ} \mathrm{C}$ and centrifuged at 9,800 $\mathrm{rcf}$ for $10 \mathrm{~min}$ using Amicon ${ }^{\circledR}$ Ultra $0.5 \mathrm{~mL}$ Centrifugal Filters (MWCO: $30 \mathrm{kDa}$ ) to remove any unbound polymer from the hybrid conjugate. The final concentrate was freeze-dried and re-dissolved for further characterisation using PAGE and HPLC analysis.

Conjugation of DBCO-p(DEGMA-co-MACYS) with mPEG azide. For the synthesis of polymer conjugate, the DBCO-p(DEGMA-co-MACYS) copolymer was dissolved in PBS and kept stirring at $4{ }^{\circ} \mathrm{C}$ for $1 \mathrm{~h}$. Then, mPEG-azide was added to the DBCO-p(DEGMA-coMACYS) copolymer solution, and the mixture was allowed to react at $4{ }^{\circ} \mathrm{C}$ for $24 \mathrm{~h}$. For a typical preparation, $4.1 \mathrm{mg}$ of DBCO-p(DEGMA-co-MACYS $)$ copolymer $\left(0.6 \times 10^{-6} \mathrm{~mol}\right)$, and $6 \mathrm{mg}$ of mPEG-azide $\left(0.3 \times 10^{-6} \mathrm{~mol}\right)$ were used (Polymer to $\mathrm{mPEG}$ azide $\left.\sim 2: 1\right)$. After conjugation, samples were heated to temperature above LCST, $30{ }^{\circ} \mathrm{C}$ for $10 \mathrm{~min}$, which made the polymer insoluble. Upon centrifugation $(14,100 \mathrm{rcf}$ for $10 \mathrm{~min})$, the polymer conjugate formed a pellet, and unreacted PEG remained in the supernatant, which could be removed. This pellet was redissolved in PBS at $4{ }^{\circ} \mathrm{C}$ and centrifuged at 9,800 $\mathrm{rcf}$ for $10 \mathrm{~min}$ using Amicon ${ }^{\circledR}$ Ultra $0.5 \mathrm{~mL}$ Centrifugal Filters (MWCO: $30 \mathrm{kDa}$ ) to remove any unbound polymer from the polymer conjugate. The final concentrate was freeze-dried and re-dissolved for further characterisation using SEC analysis.

Flow cytometry-based cellular association analysis of conjugates using a mono cell culture. PSMA+ cells were removed from tissue culture flasks by adding trypsin and resuspended in Dulbecco's PBS (DPBS) at $\mathrm{pH} 7.4$ followed by centrifugation at $131 \mathrm{rcf}$ for 5 min. The cell pellet was resuspended in $10 \%$ FCS-PBS to give $2 \times 10^{6}$ cells $/ \mathrm{mL} .100 \mu \mathrm{L}$ of the cell suspension was aliquoted into $1.5 \mathrm{~mL}$ tubes and stored on ice. $10 \mu \mathrm{g} \mathrm{mL}^{-1}$ of hybrid conjugate and PEG conjugate were added to the $100 \mu \mathrm{L}$ cell suspension and incubated for 60 
min on ice. Following incubation, the cells were centrifuged gently at $131 \mathrm{rcf}$ for $5 \mathrm{~min}$, the supernatant was pipetted off and $200 \mu \mathrm{L}$ of $10 \%$ FCS-PBS added. This wash step was repeated two more times. After the third and final wash, the supernatant was removed from the cells, and the pellet was resuspended in $100 \mu \mathrm{L}$ of $10 \%$ FCS-PBS. For each sample, data were acquired for 10,000 events using a flow cytometer (BD Accuri'TM C6, BD Biosciences, Australia) by measuring Cy5 fluorescence intensity along with the forward and side scatter. A similar protocol was used for the analysis of PSMA- cells.

Synthesis of polymeric micelles by crosslinking and its characterisation. The hybrid and PEG conjugates were dissolved in different ratios in PBS and kept for stirring at $4{ }^{\circ} \mathrm{C}$ for $2 \mathrm{~h}$. The solution temperature was then increased slowly to $30{ }^{\circ} \mathrm{C}$ under constant stirring. Oxygen was sparged into the solution for $12 \mathrm{~h}$ to facilitate disulfide crosslinking. Micelle confirmation and size were then determined by DLS and TEM. The zeta potential distribution of the micelles were determined using Zetasizer. Micelles of different antibody densities $(0,5,10,15,25,50$, 75 and $100 \%$ ) were synthesised by a similar protocol.

Interaction of micelles with serum proteins. For serum protein-micelle interaction studies, $100 \mu \mathrm{L}$ of $1 \mathrm{mg} \mathrm{mL}^{-1}$ micelles were incubated with $400 \mu \mathrm{L}$ of cell culture media (containing $10 \% \mathrm{FBS}$ ) for $1 \mathrm{~h}$ incubation at $37^{\circ} \mathrm{C}$. Samples were then centrifuged at $14,100 \mathrm{rcf}$ for $4 \mathrm{~min}$, to pellet the protein-bound micelles. The amount of unbound serum protein remaining in the supernatant was then measured by the method of Bradford assay. Briefly, $100 \mu \mathrm{L}$ of supernatant was taken in triplicate aliquots, and $100 \mu \mathrm{L}$ of Bradford reagent was added. Samples were mixed and incubated at $37^{\circ} \mathrm{C}$ for $30 \mathrm{~min}$, followed by measurement of absorbance at $595 \mathrm{~nm}$. The absorbance values were normalised against the control sample.

Stability analysis of micelles with $\mathbf{5 0 \%}$ serum proteins. For the stability analysis of micelles, $500 \mu \mathrm{L}$ of $1 \mathrm{mg} \mathrm{mL}^{-1}$ micelles were incubated with $1500 \mu \mathrm{L}$ of cell culture media (containing 
$50 \%$ FBS) for $48 \mathrm{~h}$ incubation at $37{ }^{\circ} \mathrm{C}$. Samples were then analysed using DLS for size and stability assessments. $100 \mu \mathrm{L}$ of A0 sample $\left(0.5 \mathrm{mg} \mathrm{mL}^{-1}\right)$ was taken in 96 well plate, $100 \mu \mathrm{L}$ of cell culture media (containing 50\% FBS) were added and incubated for $48 \mathrm{~h}$ at $37{ }^{\circ} \mathrm{C}$. Samples were then analysed using IVIS Lumina X5 imaging system (PerkinElmer Inc., Waltham, MA, USA) and analyzed using the Living Image software (PerkinElmer Inc.). The $620_{\mathrm{Ex}} / 670_{\mathrm{Em}}$ was used to analyze Cy5 fluorescence by micelles. Furthermore, A25 and A100 micelles were incubated in 50\% serum containing media for $48 \mathrm{~h}$, followed by centrifugation at 9,800 rcf for $10 \mathrm{~min}$ using Amicon ${ }^{\circledR}$ Ultra $0.5 \mathrm{~mL}$ Centrifugal Filters (MWCO: $3 \mathrm{kDa}$ ). The amount of Cy5 dye content in the sample was analysed at $647 \mathrm{~nm}$ using UV analysis.

\section{Flow cytometry-based cellular association analysis of micelles using a mono cell culture.} PSMA+ cells were seeded in a 12 -well plate at a concentration of $5 \times 10^{4}$ cells $\mathrm{mL}^{-1}$ and then incubated in $1 \mathrm{~mL}$ of RPMI media for $24 \mathrm{~h}$ to allow cells to adhere. Cellular association of the micelles into cells was then measured using flow cytometry after $1 \mathrm{~h}$ of exposure to $10 \mu \mathrm{g} \mathrm{mL}-1$ of micelles of varying antibody densities $(0,5,10,15,25,50,75$ and 100\%). Cells were removed from culture dishes by addition of trypsin and resuspended in Dulbecco's PBS (DPBS) at $\mathrm{pH} 7.4$ followed by centrifugation at 131 r.c.f. for 5 min. The supernatant was then removed, and cells were resuspended in $1 \mathrm{~mL}$ of DPBS. For each sample, data were acquired for 10,000 events using a flow cytometer (BD Accuri' ${ }^{\mathrm{TM}}$ C6, BD Biosciences, Australia) by measuring Cy5 fluorescence intensity along with the forward and side scatter. A similar protocol was used for the analysis of PSMA- cells. Furthermore, for competition assay, PSMA+ cells were pretreated with $10 \mu \mathrm{g} \mathrm{mL}^{-1}$ of $\mathrm{J} 591 \mathrm{scFv}$ for $30 \mathrm{~min}$, following similar protocol as mentioned above. Cellular association of the A25 and A100 micelles into PSMA+ cells were also carried out using flow cytometry after $1 \mathrm{~h}$ of exposure to varying concentrations of micelles $(1-100 \mu \mathrm{g} \mathrm{mL}-1)$. 


\section{Evaluation of intracellular distribution and localisation of micelles using confocal}

microscopy. Prior to imaging, PSMA+ cells were plated into Ibidi $^{\mathrm{TM}} \mu$-dishes and incubated with $2 \mathrm{~mL}$ of RPMI media overnight. Cells were then exposed to $10 \mu \mathrm{g} \mathrm{mL} \mathrm{L}^{-1}$ of A0, A25 and A100 micelles, incubated for $1 \mathrm{~h}$ followed by PBS wash to remove unbound micelles. Samples were imaged with an inverted Confocal Laser Scanning Microscope (Leica LASX TCS SP8) housed at the Australian Nanofabrication Facility (ANFF). In order to identify the distribution of the micelles inside the cells, the nucleus was stained using Hoechst 33342 dye (excitation $405 \mathrm{~nm}$, emission 416 - $487 \mathrm{~nm}$ ). The $633 \mathrm{~nm}$ laser was used for excitation of the Cy5-labelled polymer micelles, and the emission was collected between $645-680 \mathrm{~nm}$.

Animal studies and tumour model. All animal experiments were approved by the University of Queensland's Animal Ethics Committee and conformed to the guidelines of the Australian Code of Practice for the Care and Use of Animals for Scientific Purposes. For all animal models, eight-week-old Balb/c nude mice were acquired from the Animal Resource Centre and were allowed access to food and water ad libitum throughout the course of the experiment.

\section{In vivo biodistribution of micelles with varying antibody densities in tumour bearing mice} using optical imaging. A total of $50 \mathrm{Balb} / \mathrm{c}$ nude mice were used in this study. To establish subcutaneous tumours for in vivo targeting experiments, mice were anaesthetised using $2 \%$ isoflurane and injected subcutaneously with $2 \times 10^{6}$ PSMA+ cells (left flank) and $2 \times 10^{6}$ PSMA- cells (right flank), each in $100 \mu \mathrm{L}$ serum-free media using a $27 \mathrm{G}$ needle. Tumours were allowed to grow for 15 days before imaging experiments, at which time all mice had palpable tumours $5-10 \mathrm{~mm}$ in diameter. Micelles of varying antibody densities $(0,5,10,15$, 25, 50, 75, and $100 \%$ ) were diluted in PBS to $2.5 \mathrm{mg} \mathrm{mL}^{-1}, 100 \mu \mathrm{L}$ of samples were administered I.V. injections via the tail vein. To investigate the accumulation of micelles into the tumour, mice were sacrificed after 24 and 48 h; PC3-PIP, PC3 tumour and the major organs 
(kidney, liver, spleen, GUT, lung, heart) of all animals were harvested and imaged immediately using IVIS Lumina X5 imaging system (PerkinElmer Inc., Waltham, MA, USA) and analyzed using the Living Image software (PerkinElmer Inc.). The $620_{\mathrm{Ex}} / 670_{\mathrm{Em}}$ was used to analyze Cy5 fluorescence by micelles. The fluorescence intensities were normalised with respect to the 100\% antibody-containing micelles, which has been accounted for in Table S1.

Immune cell activation analysis with mice immune cells. Flow cytometry analysis were carried out according to the protocol by Brown et al. ${ }^{61}$ Single-cell suspensions from adult spleen or a single lobe of liver were prepared by mechanical dissociation and straining cells through a $70 \mu \mathrm{m}$ nylon strainer, using a sterile syringe plunger, into tubes containing tonicityphosphate-buffered saline/2\% fetal calf serum (PBS). Single-cell suspensions of spleen or liver containing immune cells of interest were pre-incubated with FVS (live-dead stain, BD Horizon $^{\mathrm{TM}}$ ) for $20 \mathrm{~min}$ at room temperature in the dark, followed by blocking with Fc block (1\% TruStain $\mathrm{fcX} \mathrm{X}^{\mathrm{TM}}$ (anti-mouse CD16/32; BioLegend) in PBS containing 5\% rat serum) for 10 min to block Fc receptor binding prior to surface staining with antibodies to mouse CD45, F4/80 and CD11b (BioLegend) for $1 \mathrm{~h}$ on ice in the dark. Cells were analyzed on a Fortessa X20 flow cytometer (BD Biosciences, Franklin Lakes, NJ) followed by data analysis with FlowJo software (Tree Star, 156 Inc., Ashland, OR). Furthermore, the immune cell analysis of mice blood cells ex vivo were also analysed. Micelles with varying antibody densities were added to mice blood samples and the samples were incubated for $1 \mathrm{~h}$ at $37^{\circ} \mathrm{C}$. Red blood cells were lysed and cells were phenotyped on ice for $30 \mathrm{~min}$ using titrated concentrations of antibodies against CD11b, Ly6G, CD3 and CD19 (BioLegend). Cells were analyzed on a Fortessa X20 flow cytometer (BD Biosciences, Franklin Lakes, NJ) followed by data analysis with FlowJo software (Tree Star, 156 Inc., Ashland, OR). 
Immune cell activation analysis with Human White Blood Cells. Fresh blood was collected from a healthy human volunteer (47 year old Female) into sodium heparin vacuettes (Greiner Bio-One) after obtaining informed consent in accordance with the University of Melbourne Human ethics approval 1647326.1 and the Australian National Health and Medical Research Council Statement on Ethical Conduct in Human Research. Micelles with varying antibody densities were added to human blood samples, such that their concentration in blood was $2 \mu \mathrm{g}$ $\mathrm{mL}^{-1}$, and the samples were incubated for $1 \mathrm{~h}$ at $37^{\circ} \mathrm{C}$. Red blood cells were lysed by adding Pharm Lyse buffer (BD) and incubated for 15-30 min in ice and washed twice with PBS (500 g, $7 \mathrm{~min}$ ). Cells were phenotyped on ice for $30 \mathrm{~min}$ using titrated concentrations of antibodies against CD66b BV421 (G10F5, BD), CD14 APC-H7 (MФP9, BD), CD19 BV650 (HIB19, Biolegend), CD3 AF700 (SP34-2, BD), CD56 PE (B159, BD), HLA-DR PerCP-Cy5.5 (G466, BD), lineage-1 cocktail FITC (BD). Unbound antibodies were removed by washing and centrifugation $(500 \mathrm{~g}, 7 \mathrm{~min})$ with a cold $\left(4{ }^{\circ} \mathrm{C}\right) \mathrm{PBS}$ buffer containing $0.5 \% \mathrm{w} / \mathrm{v}$ BSA and 2 mM EDTA. Cells were fixed in 1\% w/v formaldehyde in PBS. The samples were directly used for cell association analysis by flow cytometry. The data were processed using FlowJo software.

\section{Statistical analysis}

Data for each measurement represent mean \pm standard deviation, $\mathrm{n}=3$. Statistical analysis was performed using Graphpad Prism 8.1 software. The statistical comparisons were conducted using One-way ANOVA or Two-way ANOVA, followed by the Tukey multicomparison test. $\mathrm{P}$ values $<0.05$ were considered statistically significant $(*=\mathrm{p}<0.05, * *=\mathrm{p}<0.01, * * *=\mathrm{p}<$ $0.001, * * * *=\mathrm{p}<0.0001)$

\section{ASSOCIATED CONTENT}




\section{Supporting Information}

Supporting Information is available free of charge at http://pubs.acs.org/doi/10.1021/xxxxx

${ }^{1} H$ NMR of polymer precursors, turbidity scans showing LCST behaviour of polymers, SDSPAGE conjugate analysis, DLS size data of mPEG and $s c F v$, cell association assays for conjugates, DLS size data of conjugates in serum, DLS size, zeta and stability analysis of micelles, competition assay of the micelles, fluorescence images of organs following injection of various constructs, micelle interaction with serum proteins in serum, interaction of micelles with immune cells in mice blood

\section{Financial Interest Statement}

The authors declare no competing financial interest.

\section{AUTHOR INFORMATION}

\section{Corresponding Author}

*E-mail: k.thurecht@uq.edu.au

\section{ORCID}

Amal J Sivaram: 0000-0002-6046-3272

Andri Wardiana: 0000-0003-1335-1320

Sheilajen Alcantara

Stefan E. Sonderegger: 0000-0001-9873-0885

Nicholas L. Fletcher: 0000-0002-2993-833X 
Zachary H. Houston: 0000-0001-9738-4917

Christopher B. Howard: 0000-0001-9797-8686

Stephen M. Mahler: 0000-0003-2403-1437

Cameron Alexander: 0000-0001-8337-1875

Stephen J. Kent: 0000-0002-8539-4891

Craig A. Bell: 0000-0002-8986-2795

Kristofer J. Thurecht: 0000-0002-4100-3131

\section{Author Contributions}

A.J.S, C.A.B, and K.J.T conceived the project. A.J.S and C.A.B designed the polymer synthesis and characterisations. A.W, C.B.H and S.M.M designed the scFv synthesis. S.A and S.J.K designed the human blood analysis, S.E.S designed the mice immune cell activation analysis. N.L.F and Z.H.H designed the in vivo biodistribution studies. All the authors analysed the data. The manuscript was written through contributions of all authors. All authors have given approval to the final version of the manuscript.

\section{ACKNOWLEDGEMENTS}

The authors acknowledge the facilities, and the scientific and technical assistance of the National Imaging Facility at the Centre for Advanced Imaging, University of Queensland. Funding for this research is acknowledged from the National Health and Medical Research Council (APP1099321 and APP1148582 (K.J.T.); APP1054569 (C.A.B.)) and the Australian Research Council (LP150100703 (K.J.T.)). This work was performed in part at the Queensland node of the Australian National Fabrication Facility (ANFF), a company established under the 
National Collaborative Research Infrastructure Strategy to provide nano- and microfabrication facilities for Australia's researchers. This research was conducted and funded by the ARC Centre of Excellence in Convergent Bio-Nano Science and Technology (CE140100036) and in part by the ARC Training Centre for Innovation in Biomedical Imaging Technologies (IC170100035).

\section{REFERENCES}

1. Shi, J.; Kantoff, P. W.; Wooster, R.; Farokhzad, O. C., Cancer Nanomedicine: Progress, Challenges and Opportunities. Nat. Rev. Cancer 2017, 17, 20-37.

2. Wicki, A.; Witzigmann, D.; Balasubramanian, V.; Huwyler, J., Nanomedicine in Cancer Therapy: Challenges, Opportunities, and Clinical Applications. J. Controlled Release 2015, 200, 138-157.

3. Muthu, M. S.; Leong, D. T.; Mei, L.; Feng, S.-S., Nanotheranostics - Application and Further Development of Nanomedicine Strategies for Advanced Theranostics. Theranostics 2014, 4, 660-677.

4. Wilhelm, S.; Tavares, A. J.; Dai, Q.; Ohta, S.; Audet, J.; Dvorak, H. F.; Chan, W. C., Analysis of Nanoparticle Delivery to Tumours. Nat. Rev. Mater. 2016, 1, 16014.

5. Fang, J.; Nakamura, H.; Maeda, H., The EPR Effect: Unique Features of Tumor Blood Vessels for Drug Delivery, Factors Involved, and Limitations and Augmentation of the Effect. Adv. Drug Delivery Rev. 2011, 63, 136-151.

6. Bjornmalm, M.; Thurecht, K. J.; Michael, M.; Scott, A. M.; Caruso, F., Bridging BioNano Science and Cancer Nanomedicine. ACS Nano 2017, 11, 9594-9613.

7. Yoo, J.-W.; Chambers, E.; Mitragotri, S., Factors That Control the Circulation Time of Nanoparticles in Blood: Challenges, Solutions and Future Prospects. Curr. Pharm. Des. 2010, $16,2298-2307$. 
8. Zhang, S.; Li, J.; Lykotrafitis, G.; Bao, G.; Suresh, S., Size-Dependent Endocytosis of Nanoparticles. Adv. Mater. 2009, 21, 419-424.

9. Cui, J.; Ju, Y.; Houston, Z. H.; Glass, J. J.; Fletcher, N. L.; Alcantara, S.; Dai, Q.; Howard, C. B.; Mahler, S. M.; Wheatley, A. K.; De Rose, R.; Brannon, P. T.; Paterson, B. M.; Donnelly, P. S.; Thurecht, K. J.; Caruso, F.; Kent, S. J., Modulating Targeting of Poly(Ethylene Glycol) Particles to Tumor Cells Using Bispecific Antibodies. Adv. Healthcare Mater. 2019, $8,1801607$.

10. Alkilany, A. M.; Zhu, L.; Weller, H.; Mews, A.; Parak, W. J.; Barz, M.; Feliu, N., Ligand Density on Nanoparticles: A Parameter with Critical Impact on Nanomedicine. $A d v$. Drug Delivery Rev. 2019, 143, 22-36.

11. Pelaz, B.; del Pino, P.; Maffre, P.; Hartmann, R.; Gallego, M.; Rivera-Fernandez, S.; de la Fuente, J. M.; Nienhaus, G. U.; Parak, W. J., Surface Functionalization of Nanoparticles with Polyethylene Glycol: Effects on Protein Adsorption and Cellular Uptake. ACS Nano 2015, 9, 6996-7008.

12. Moody, P. R.; Sayers, E. J.; Magnusson, J. P.; Alexander, C.; Borri, P.; Watson, P.; Jones, A. T., Receptor Crosslinking: A General Method to Trigger Internalization and Lysosomal Targeting of Therapeutic Receptor: Ligand Complexes. Mol. Ther. 2015, 23, 18881898.

13. Colombo, M.; Fiandra, L.; Alessio, G.; Mazzucchelli, S.; Nebuloni, M.; De Palma, C.; Kantner, K.; Pelaz, B.; Rotem, R.; Corsi, F. ; Parak, W. J.; Prosperi, D., Tumour Homing and Therapeutic Effect of Colloidal Nanoparticles Depend on the Number of Attached Antibodies. Nat. Commun. 2016, 7, 13818.

14. Sayers, E. J.; Magnusson, J. P.; Moody, P. R.; Mastrotto, F.; Conte, C.; Brazzale, C.; Borri, P.; Caliceti, P.; Watson, P.; Mantovani, G.; Aylott, J.; Salmaso, S.; Jones, A. T.; 
Alexander, C., Switching of Macromolecular Ligand Display by Thermoresponsive Polymers Mediates Endocytosis of Multiconjugate Nanoparticles. Bioconjugate Chem. 2018, 29, 10301046.

15. Makwana, H.; Mastrotto, F.; Magnusson, J. P.; Sleep, D.; Hay, J.; Nicholls, K. J.; Allen, S.; Alexander, C., Engineered Polymer-Transferrin Conjugates as Self-Assembling Targeted Drug Delivery Systems. Biomacromolecules 2017, 18, 1532-1543.

16. Poon, Z.; Chen, S.; Engler, A. C.; Lee, H. i.; Atas, E.; von Maltzahn, G.; Bhatia, S. N.; Hammond, P. T., Ligand-Clustered "Patchy" Nanoparticles for Modulated Cellular Uptake and In Vivo Tumor Targeting. Angew. Chem. 2010, 49, 7266-7270.

17. Griebenow, K.; Klibanov, A. M., On Protein Denaturation in Aqueous-Organic Mixtures But Not in Pure Organic Solvents. J. Am. Chem. Soc. 1996, 118, 11695-11700.

18. Koo, H.; Lee, S.; Na, J. H.; Kim, S. H.; Hahn, S. K.; Choi, K.; Kwon, I. C.; Jeong, S. Y.; Kim, K., Bioorthogonal Copper-Free Click Chemistry In Vivo for Tumor-Targeted Delivery of Nanoparticles. Angew. Chem. 2012, 51, 11836-11840.

19. Gibson, M. I.; Fröhlich, E.; Klok, H. A., Postpolymerization Modification of Poly(Pentafluorophenyl Methacrylate): Synthesis of a Diverse Water-Soluble Polymer Library. J. Polym. Sci., Part A: Polym. Chem. 2009, 47, 4332-4345.

20. Kim, D. W.; Ahn, D.-S.; Oh, Y.-H.; Lee, S.; Kil, H. S.; Oh, S. J.; Lee, S. J.; Kim, J. S.; Ryu, J. S.; Moon, D. H.; Chi, D. Y., A New Class of SN2 Reactions Catalyzed by Protic Solvents: Facile Fluorination for Isotopic Labeling of Diagnostic Molecules. J. Am. Chem. Soc. 2006, 128, 16394-16397.

21. Gyarmati, B.; Némethy, Á.; Szilágyi, A., Reversible Disulphide Formation in Polymer Networks: A Versatile Functional Group From Synthesis to Applications. Eur. Polym. J. 2013, 49, 1268-1286. 
22. Wang, C.; Yan, Q.; Liu, H.-B.; Zhou, X.-H.; Xiao, S.-J., Different EDC/NHS Activation Mechanisms between PAA and PMAA Brushes and the Following Amidation Reactions. Langmuir 2011, 27, 12058-12068.

23. Smith-Jones, P. M.; Vallabhajosula, S.; Navarro, V.; Bastidas, D.; Goldsmith, S. J.; Bander, N. H., Radiolabeled Monoclonal Antibodies Specific to the Extracellular Domain of Prostate-Specific Membrane Antigen: Preclinical Studies in Nude Mice Bearing LNCaP Human Prostate Tumor. J. Nucl. Med. 2003, 44, 610-617.

24. Lang, K.; Chin, J. W., Cellular Incorporation of Unnatural Amino Acids and Bioorthogonal Labeling of Proteins. Chem. Rev. 2014, 114, 4764-4806.

25. Sayers, C. T.; Mantovani, G.; Ryan, S. M.; Randev, R. K.; Keiper, O.; Leszczyszyn, O. I.; Blindauer, C.; Brayden, D. J.; Haddleton, D. M., Site-Specific N-Terminus Conjugation of Poly(mPEG 1100) Methacrylates to Salmon Calcitonin: Synthesis and Preliminary Biological Evaluation. Soft Matter 2009, 5, 3038-3046.

26. Decker, C. G.; Maynard, H. D., Degradable PEGylated Protein Conjugates Utilizing RAFT Polymerization. Eur. Polym. J. 2015, 65, 305-312.

27. Samanta, D.; McRae, S.; Cooper, B.; Hu, Y.; Emrick, T.; Pratt, J.; Charles, S. A., EndFunctionalized Phosphorylcholine Methacrylates and Their Use in Protein Conjugation. Biomacromolecules 2008, 9, 2891-2897.

28. Caster, J. M.; Patel, A. N.; Zhang, T.; Wang, A., Investigational Nanomedicines in 2016: A Review of Nanotherapeutics Currently Undergoing Clinical Trials. Wiley Interdiscip. Rev.: Nanomed. Nanobiotechnol. 2017, 9, e1416.

29. Chuang, K.-H.; Kao, C.-H.; Roffler, S. R.; Lu, S.-J.; Cheng, T.-C.; Wang, Y.-M.; Chuang, C.-H.; Hsieh, Y.-C.; Wang, Y.-T.; Wang, J.-Y.; Weng, K.-Y.; Cheng, T.-L., 
Development of an Anti-Methoxy Poly(Ethylene Glycol)( $\alpha$-mPEG) Cell-Based Capture System to Measure mPEG and mPEGylated Molecules. Macromolecules 2014, 47, 6880-6888. 30. Ghosh, A.; Heston, W. D., Tumor Target Prostate Specific Membrane Antigen (PSMA) and Its Regulation in Prostate Cancer. J. Cell. Biochem. 2004, 91, 528-539.

31. Rapoport, N., Physical Stimuli-Responsive Polymeric Micelles for Anti-Cancer Drug Delivery. Prog. Polym. Sci. 2007, 32, 962-990.

32. van Nostrum, C. F., Covalently Cross-Linked Amphiphilic Block Copolymer Micelles. Soft Matter 2011, 7, 3246-3259.

33. Eliezar, J.; Scarano, W.; Boase, N. R.; Thurecht, K. J.; Stenzel, M. H., In Vivo Evaluation of Folate Decorated Cross-Linked Micelles for the Delivery of Platinum Anticancer Drugs. Biomacromolecules 2015, 16, 515-523.

34. Hu, Z.; Cai, T.; Chi, C., Thermoresponsive Oligo(Ethylene Glycol)-MethacrylateBased Polymers and Microgels. Soft Matter 2010, 6, 2115-2123.

35. Chanakira, A.; Chikwana, E.; Peyton, D. H.; Simoyi, R. H., Oxyhalogen-Sulfur Chemistry - Kinetics and Mechanism of the Oxidation of Cysteamine by Acidic Iodate and Iodine. Can. J. Chem. 2006, 84, 49-57.

36. Steinhauer, W.; Keul, H.; Möller, M., Synthesis of Reversible and Irreversible CrossLinked (M)PEG-(meth)acrylate Based Functional Copolymers. Polym. Chem. 2011, 2, 1803 1814.

37. Elias, D. R.; Poloukhtine, A.; Popik, V.; Tsourkas, A., Effect of Ligand Density, Receptor Density, and Nanoparticle Size on Cell Targeting. Nanomedicine (N. Y., NY, U. S.) 2013, 9, 194-201.

38. Yuan, H.; Li, J.; Bao, G.; Zhang, S., Variable Nanoparticle-Cell Adhesion Strength Regulates Cellular Uptake. Phys. Rev. Lett. 2010, 105, 138101. 
39. Thurber, G. M.; Weissleder, R., Quantitating Antibody Uptake In Vivo: Conditional Dependence on Antigen Expression Levels. Mol. Imaging Biol. 2011, 13, 623-632.

40. Such, G. K.; Johnston, A. P., Understanding Cell Interactions Using Modular Nanoparticle Libraries. Aust. J. Chem. 2019, 72, 595-599.

41. Zern, B. J.; Chacko, A.-M.; Liu, J.; Greineder, C. F.; Blankemeyer, E. R.; Radhakrishnan, R.; Muzykantov, V., Reduction of Nanoparticle Avidity Enhances the Selectivity of Vascular Targeting and PET Detection of Pulmonary Inflammation. ACS Nano 2013, 7, 2461-2469.

42. Caré, B. R.; Soula, H. A., Impact of Receptor Clustering on Ligand Binding. BMC Syst. Biol. 2011, 5, 1-13.

43. Schmidt, D.; Bihr, T.; Fenz, S.; Merkel, R.; Seifert, U.; Sengupta, K.; Smith, A.-S., Crowding of Receptors Induces Ring-Like Adhesions in Model Membranes. Biochim. Biophys. Acta, Mol. Cell Res. 2015, 1853, 2984-2991.

44. Yong, K. W.; Yuen, D.; Chen, M. Z.; Johnston, A. P., Engineering the Orientation, Density, and Flexibility of Single-Domain Antibodies on Nanoparticles to Improve Cell Targeting. ACS Appl. Mater. Interfaces 2020, 12, 5593-5600.

45. Xu, S.; Olenyuk, B. Z.; Okamoto, C. T.; Hamm-Alvarez, S. F., Targeting ReceptorMediated Endocytotic Pathways with Nanoparticles: Rationale and Advances. Adv. Drug Delivery Rev. 2013, 65, 121-138.

46. Liu, A. P.; Aguet, F.; Danuser, G.; Schmid, S. L., Local Clustering of Transferrin Receptors Promotes Clathrin-Coated Pit Initiation. J. Cell Biol. 2010, 191, 1381-1393.

47. Rosenblum, D.; Joshi, N.; Tao, W.; Karp, J. M.; Peer, D., Progress and Challenges towards Targeted Delivery of Cancer Therapeutics. Nat. Commun. 2018, 9, 1410. 
48. Shi, C.; Pamer, E. G., Monocyte Recruitment During Infection and Inflammation. Nat. Rev. Immunol. 2011, 11, 762-774.

49. Schaller, E.; Macfarlane, A. J.; Rupec, R. A.; Gordon, S.; McKnight, A. J.; Pfeffer, K., Inactivation of the F4/80 Glycoprotein in the Mouse Germ Line. Mol. Cell. Biol. 2002, 22, $8035-8043$

50. Poon, W.; Zhang, Y.-N.; Ouyang, B.; Kingston, B. R.; Wu, J. L.; Wilhelm, S.; Chan, W. C., Elimination Pathways of Nanoparticles. ACS Nano 2019, 13, 5785-5798.

51. Walkey, C. D.; Chan, W. C., Understanding and Controlling the Interaction of Nanomaterials with Proteins in a Physiological Environment. Chem. Soc. Rev. 2012, 41, 27802799.

52. Weiss, A. C.; Kelly, H. G.; Faria, M.; Besford, Q. A.; Wheatley, A. K.; Ang, C.-S.; Crampin, E. J.; Caruso, F.; Kent, S. J., Link between Low-Fouling and Stealth: A Whole Blood Biomolecular Corona and Cellular Association Analysis on Nanoengineered Particles. ACS Nano 2019, 13, 4980-4991.

53. Tenzer, S.; Docter, D.; Kuharev, J.; Musyanovych, A.; Fetz, V.; Hecht, R.; Schlenk, F.; Fischer, D.; Kiouptsi, K.; Reinhardt, C.; Landfester, K.; Schild, H.; Maskos, M.; Knauer, S. K.; Stauber, R. H., Rapid Formation of Plasma Protein Corona Critically Affects Nanoparticle Pathophysiology. Nat. Nanotechnol. 2013, 8, 772-781.

54. Walkey, C. D.; Olsen, J. B.; Song, F.; Liu, R.; Guo, H.; Olsen, D. W. H.; Cohen, Y.; Emili, A.; Chan, W. C., Protein Corona Fingerprinting Predicts the Cellular Interaction of Gold and Silver Nanoparticles. ACS Nano 2014, 8, 2439-2455.

55. Boraschi, D.; Italiani, P.; Palomba, R.; Decuzzi, P.; Duschl, A.; Fadeel, B.; Moghimi, S. M., Nanoparticles and Innate Immunity: New Perspectives on Host Defence. Semin. Immunol. 2017, 34, 33-51. 
56. Glass, J. J.; Chen, L.; Alcantara, S.; Crampin, E. J.; Thurecht, K. J.; De Rose, R.; Kent,

S. J., Charge Has a Marked Influence on Hyperbranched Polymer Nanoparticle Association in Whole Human Blood. ACS Macro Lett. 2017, 6, 586-592.

57. Fuchs, A. V.; Tse, B. W.; Pearce, A. K.; Yeh, M. C.; Fletcher, N. L.; Huang, S. S.; Heston, W. D.; Whittaker, A. K.; Russell, P. J.; Thurecht, K. J., Evaluation of Polymeric Nanomedicines Targeted to PSMA: Effect of Ligand on Targeting Efficiency. Biomacromolecules 2015, 16, 3235-47.

58. Convertine, A. J.; Benoit, D. S.; Duvall, C. L.; Hoffman, A. S.; Stayton, P. S., Development of a Novel Endosomolytic Diblock Copolymer for siRNA Delivery. $J$. Controlled Release 2009, 133, 221-229.

59. Nakajima, T.; Mitsunaga, M.; Bander, N. H.; Heston, W. D.; Choyke, P. L.; Kobayashi, H., Targeted, Activatable, In Vivo Fluorescence Imaging of Prostate-Specific Membrane Antigen (PSMA) Positive Tumors Using the Quenched Humanized J591 AntibodyIndocyanine Green (ICG) Conjugate. Bioconjugate Chem. 2011, 22, 1700-1705.

60. Faria, M.; Björnmalm, M.; Thurecht, K. J.; Kent, S. J.; Parton, R. G.; Kavallaris, M.; Johnston, A. P.; Gooding, J. J.; Corrie, S. R.; Boyd, B. J.; Thordarson, P.; Whittaker, A. K.; Stevens, M. M.; Prestidge, C. A.; Porter, C. J. H.; Parak, W. J.; Davis, T. P.; Crampin, E. J.; Caruso, F., Minimum Information Reporting in Bio-Nano Experimental Literature. Nat. Nanotechnol. 2018, 13, 777-785.

61. Brown, F. C.; Scott, N.; Rank, G.; Collinge, J. E.; Vadolas, J.; Vickaryous, N.; Whitelaw, N.; Whitelaw, E.; Kile, B. T.; Jane, S. M.; Curtis, D. J., ENU Mutagenesis Identifies the First Mouse Mutants Reproducing Human $\beta$-Thalassemia at the Genomic Level. Blood Cells, Mol., Dis. 2013, 50, 86-92. 


\section{TOC Graphic}

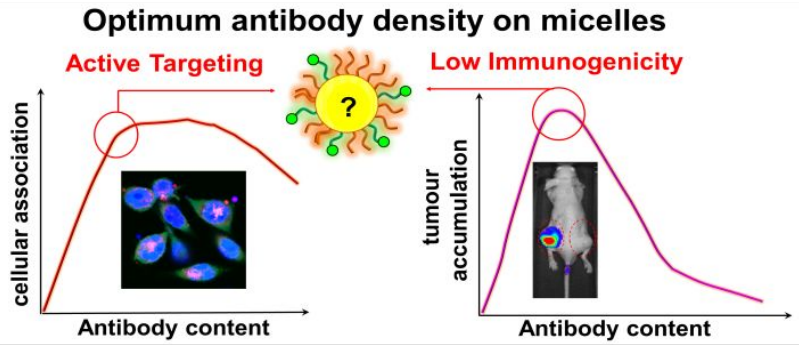

